Article

\title{
Facile, Regio- and Diastereoselective Synthesis of Spiro-Pyrrolidine and Pyrrolizine Derivatives and Evaluation of Their Antiproliferative Activities
}

Abdulrahman I. Almansour ${ }^{1}$, Raju Suresh Kumar ${ }^{1}$, Farzana Beevi ${ }^{2}$, Amir Nasrolahi Shirazi ${ }^{3,6}$, Hasnah Osman $^{4}$, Rusli Ismail ${ }^{7}$, Tan Soo Choon ${ }^{5}$, Brian Sullivan ${ }^{3}$, Kellen McCaffrey ${ }^{3}$, Alaa Nahhas ${ }^{3}$, Keykavous Parang ${ }^{3,6, *}$ and Mohamed Ashraf Ali ${ }^{2,5, *}$

1 Department of Chemistry, College of Science, King Saud University, P.O.Box 2455, Riyadh 11451, Saudi Arabia

2 New Drug Discovery Research, Department of Medicinal Chemistry, Sunrise University, Alwar, Rajasthan-301030, India

3 Department of Biomedical and Pharmaceutical Sciences, College of Pharmacy, University of Rhode Island, Kingston, RI 02881, USA

4 School of Chemical Sciences, Universiti Sains Malaysia, Minden 11800, Penang, Malaysia.

5 Institute for Research in Molecular Medicine, Universiti Sains Malaysia, Minden 11800, Penang, Malaysia

6 School of Pharmacy, Chapman University, Irvine, CA 92618, USA

7 Centre of Excellence for Research in AIDS, University Malaya, Kuala Lumpur 50603, Malaysia

* Authors to whom correspondence should be addressed; E-Mails: parang@chapman.edu (K.P.); drashraf@usm.my (M.A.A.); Tel.: +1-401-874-4471 (K.P.); Fax: +1-401-874-5787 (K.P.).

Received: 29 May 2014; in revised form: 24 June 2014 / Accepted: 1 July 2014 /

Published: 10 July 2014

Abstract: A number of novel spiro-pyrrolidines/pyrrolizines derivatives were synthesized through [3+2]-cycloaddition of azomethine ylides with 3,5-bis[(E)arylmethylidene]tetrahydro-4(1H)-pyridinones 2a-n. Azomethine ylides were generated in situ from the reaction of $1 H$-indole-2,3-dione (isatin, 3) with $N$-methylglycine (sarcosine), phenylglycine, or proline. All compounds $(50 \mu \mathrm{M})$ were evaluated for their antiproliferative activity against human breast carcinoma (MDA-MB-231), leukemia lymphoblastic (CCRF-CEM), and ovarian carcinoma (SK-OV-3) cells. $N$ - $\alpha$-Phenyl substituted spiro-pyrrolidine derivatives (5a-n) showed higher antiproliferative activity in MDA-MB-231 than other cancer cell lines. Among spiro-pyrrolizines $\mathbf{6 a}-\mathbf{n}$, a number of derivatives including $\mathbf{6 a}-\mathbf{c}$ and $\mathbf{6 i -}-\mathbf{m}$ showed a comparable activity with doxorubicin in all 
three cell lines. Among all compounds in three classes, $\mathbf{6 a}, \mathbf{6 b}$, and $\mathbf{6 m}$, were found to be the most potent derivatives showing $64 \%, 87 \%$, and $74 \%$ antiproliferative activity in MDA-MB-231, SK-OV-3, and CCRF-CEM cells, respectively. Compound $6 \mathbf{b}$ showed an $\mathrm{IC}_{50}$ value of $3.6 \mu \mathrm{M}$ in CCRF-CEM cells. These data suggest the potential antiproliferative activity of spiro-pyrrolidines/pyrrolizines.

Keywords: antiproliferative activity; diastereoselective synthesis; pyrrolizine; regio-selective synthesis; spiro-pyrolidine

\section{Introduction}

Multicomponent reactions (MCRs) [1-5] constitute an efficient and powerful tool for the synthesis of novel organic compounds. MCRs take advantage of several distinct properties including low cost, accelerated reaction time, and eco-friendly reaction conditions [6-9], and provide an expeditious and elegant access to libraries of complex structures and diversified compounds. Thus, MCRs are widely used in combinatorial chemistry and complicated synthetic procedures [10-15].

Functionalized pyrrolidines and pyrrolizines are the central skeleton of numerous alkaloids and constitute classes of compounds with significant biological properties, such as anticancer activity [16-18]. Heterocycles containing piperidine sub-structures display important biological activities, such as anticancer activity as well as being useful as synthons in the construction of alkaloid natural products [19-21]. Dimmock et al. reported the synthesis of 3,5-bis[(E)-arylmethyl idene] tetrahydro4(1H)-pyridinones and their corresponding substituted analogues as potential anticancer agents with modest to high activity [22].

Several spiro-compounds have shown very promising biologically activity with potential applications as anticancer [21-25], antibacterial [26,27], anticonvulsant [28-30], anti-tuberculosis [31], and anti-Alzheimer's disease agents [31]. Spiro compounds have also been recently used as antioxidant agents [32,33].

[3+2]-Cycloaddition of azomethine ylides with olefinic dipolarophiles has been reported as one of the main methods for generating highly functionalized heterocyclic scaffolds as diversified chemical libraries [33-39]. Inspired by the previously reported biological potency of spiro compounds and as a part of our ongoing research in the construction of novel hybrid heterocycles, herein we report the synthesis of three different classes of spiro-pyrrolidines and spiro-pyrrolizines derivatives by the $[3+2]$-cycloaddition of azomethine ylides with 3,5-bis $[(E)$-arylmethylidene]tetrahydro- $4(1 H)$-pyridinones and evaluation of their anticancer activities.

\section{Results and Discussion}

\subsection{Chemistry}

The synthesis of the prerequisite 3,5-bis[(E)-arylmethyl idene]tetrahydro-4(1H)-pyridinones 2 was carried out according to the previously reported procedure from the reaction of an appropriate aryl aldehyde (2 mmol) with 4-piperidone hydrochloride monohydrate $(1,1 \mathrm{mmol})$ in acetic acid [25]. 
Azomethine ylides were generated in situ from the reaction of $1 H$-indole-2,3-dione (isatin, 3) with (i) $\mathrm{N}$-methylglycine (sarcosine); (ii) phenylglycine; and (iii) proline. The [3+2]-cycloaddition of azomethine ylides with the exocyclic dipolarophiles (2) afforded the novel $N$-methyl substituted spiro-pyrrolidines $\mathbf{4 a}-\mathbf{n}, N$ - $\alpha$-phenyl substituted spiro-pyrrolidine derivatives $\mathbf{5 a}-\mathbf{n}$, and spiro-pyrrolizines $\mathbf{6 a}-\mathbf{n}$, respectively, in reasonable yields. All the reactions were performed by heating the mixture of 2a-n, $1 H$-indole-2,3-dione (3) and $N$-methylglycine/phenylglycine/proline in a molar ratio 1:1.1:1.1 under reflux in methanol. All compounds were isolated as in a form of racemic mixtures in $82 \%-94 \%$ (Scheme 1).

Scheme 1. Synthesis of piperidone grafted spiroheterocycles.

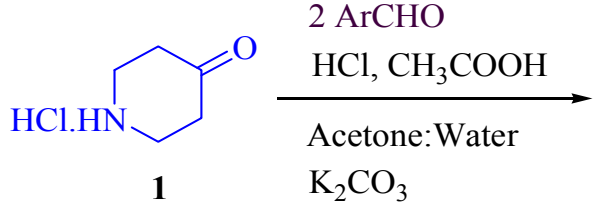

$$
\begin{array}{llr}
\mathbf{b}=2-\mathrm{MeC}_{6} \mathrm{H}_{4} & \mathbf{g}=2,4-\mathrm{Cl}_{2} \mathrm{C}_{6} \mathrm{H}_{3} & \mathbf{I}=4-\mathrm{BrC}_{6} \mathrm{H}_{4} \\
\mathbf{c}=2-\mathrm{OMeC}_{6} \mathrm{H}_{4} & \mathbf{h}=3-\mathrm{NO}_{2} \mathrm{C}_{6} \mathrm{H}_{4} & \mathbf{m}=4-\mathrm{FC}_{6} \mathrm{H}_{4} \\
\mathbf{d}=2-\mathrm{ClC}_{6} \mathrm{H}_{4} & \mathbf{i}=4-\mathrm{MeC}_{6} \mathrm{H}_{4} & \mathbf{n}=1-\text { Naphthyl } \\
\mathbf{e}=2-\mathrm{BrC}_{6} \mathrm{H}_{4} & \mathbf{j}=4-\mathrm{OMeC}_{6} \mathrm{H}_{4} &
\end{array}
$$$$
\text { 2, Ar: } \mathbf{a}=\mathrm{C}_{6} \mathrm{H}_{5} \quad \mathbf{f}=2-\mathrm{FC}_{6} \mathrm{H}_{4} \quad \mathbf{k}=4-\mathrm{ClC}_{6} \mathrm{H}_{4}
$$
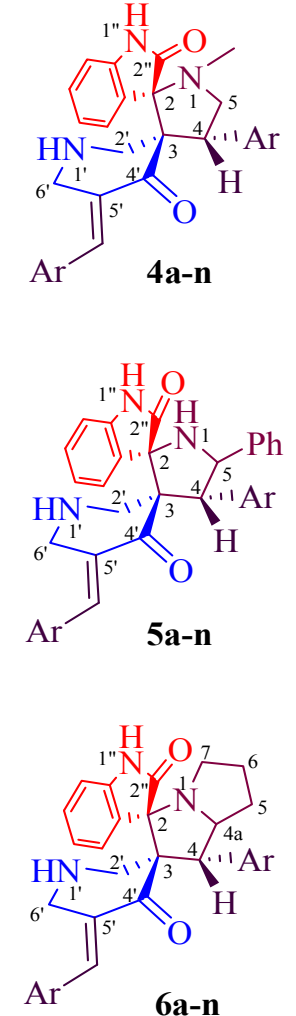

For instance, the synthesis of spiro-pyrrolidine derivatives 4 and 5 by using $N$-methylglycine or phenylglycine, respectively, was completed within $1 \mathrm{~h}$. In comparison, the reaction with proline took $30 \mathrm{~min}$ to afford the corresponding spiro-pyrrolizine derivatives 6. All substrates carrying aromatic rings with electron-withdrawing and electron-donating substituents afforded the product in high to excellent yields within approximately similar time ranges (Table S1, Supporting Information). The cycloaddition reaction worked well regardless of the position and electronic or steric properties of the substituents at the aromatic rings of 2 . The reaction of $1 \mathrm{H}$-indole-2,3-dione with $\mathrm{N}$-methylglycine, phenylglycine, or proline afforded the corresponding azomethine ylide, which was added to one of the exocyclic $\mathrm{C}=\mathrm{C}$ bonds of the bisdipolarophile $\mathbf{2}$ to form the corresponding cycloadducts $\mathbf{4}, \mathbf{5}$, or $\mathbf{6}$, respectively. The structures of cycloadducts 4-6 were characterized using elemental analysis, FT-IR, ${ }^{1} \mathrm{H},{ }^{13} \mathrm{C}$ and $2 \mathrm{D}-\mathrm{NMR}$ spectroscopic analysis.

A proposed mechanism for the formation of spiro-pyrrolidines is shown in Scheme 2. It is noteworthy to mention that all reactions proceeded chemoselectively since the dipole addition was 
occurred only to the available $\mathrm{C}=\mathrm{C}$ bond rather than $\mathrm{C}=\mathrm{O}$ functional group of 2 . All reactions were also found to be regioselective, which can be viewed as the result of a preferential attack of the nucleophilic carbon of the azomethine ylide to the end of the enone fragment of the dipolarophile 2 to give 4, 5, or $\mathbf{6}$. Another significant advantage of this method is that all the above reactions proceeded via complete stereoselectivity leading to the production of a single stereoisomer despite the presence of many stereocenters in the cycloadducts.

Scheme 2. Mechanism for the formation of spiro-pyrrolidines.
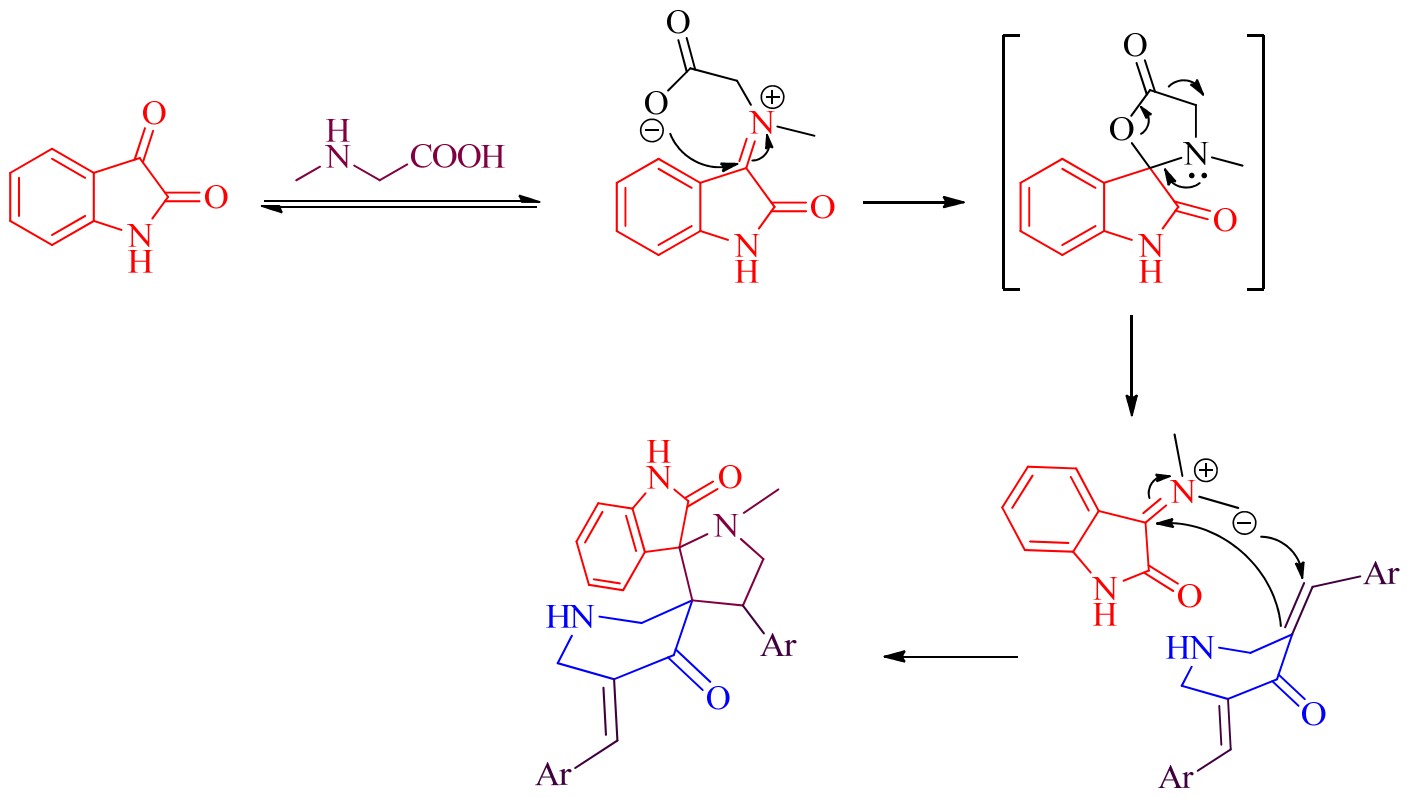

\subsection{Biological Evaluation}

Starting building blocks $2 \mathbf{a}-\mathbf{n}$ and three classes of synthesized compounds $3 \mathbf{a}-\mathbf{n}, \mathbf{4 a}-\mathbf{n}$, and $\mathbf{6 a}-\mathbf{n}$ $(50 \mu \mathrm{M})$ were evaluated for their effect on proliferation of human ovarian adenocarcinoma (SK-OV-3), breast adenocarcinoma (MDA-MB-231), and lymphoblastic leukemia (CCRF-CEM). Doxorubicin (Dox) and DMSO were used as positive and negative controls, respectively.

The results for cell proliferation at $50 \mu \mathrm{M}$ after $72 \mathrm{~h}$ for 3,5-bis[(E)-arylmethylidene]tetrahydro4(1H)-pyridinones $\mathbf{2 a}-\mathbf{n}$ are shown in Figure 1. Compounds $\mathbf{2} \mathbf{a}-\mathbf{g}$ inhibited the cell proliferation of MDA-MB-231 cells by $85 \%-88 \%$. The presence of a wide range of substituents on two side aromatic rings was tested. The majority of derivatives containing electron donating groups including methyl and methoxy, showed higher antiproliferative actvity than compounds with electron withdrawing groups e.g., nitro in MDA-MB-231 cells after $72 \mathrm{~h}$ incubation. Compounds with substitutions on para positions were exhibited slightly lower inhibition activity. This trend was also observed in SK-OV-3 and CCRF-CEM cells. All the compounds in this class showed higher antiproliferative activity in MDA-MB-231 than CCRF-CEM and SK-OV-3 cells. Thus, MDA-MB-231 cells were found to be the most sensitive cell line to these compounds among the three that have tested.

$\mathrm{N}$-Methyl spiro-pyrrolidine derivatives 4a-n antiproliferative activities are shown in Figure 2. Among all compounds in this class, $\mathbf{4 k}, \mathbf{4 n}$, and $\mathbf{4 l}$ showed the highest antiproliferative activity in CCRF-CEM, MDA-MB-231, and SK-OV-3 cells by 58\%, 80\%, and 70\% inhibition, respectively. 
Most of the compounds showed higher antiproliferative activity in MDA-MB-231 cells than other cancer cell lines. However, some compounds including 4i, 4k, 4l, 4m, and 4n exhibited a consistent potency in all cell lines. The position of substituents on aromatic rings was found to be critical in antiproliferative activity against SK-OV-3 and MDA-MB-231 cells. Compounds $\mathbf{4 i - \mathbf { m }}$ with the para substituents on the aromatic rings showed significantly higher activity when compared with compounds $\mathbf{4 a}-\mathbf{h}$ with substituents on the ortho and meta positions.

Figure 1. Antiproliferative activity of 3,5-bis[(E)-arylmethylidene $]$ tetrahydro $-4(1 H)$-pyridinones $\mathbf{2 a}-\mathbf{n}$.

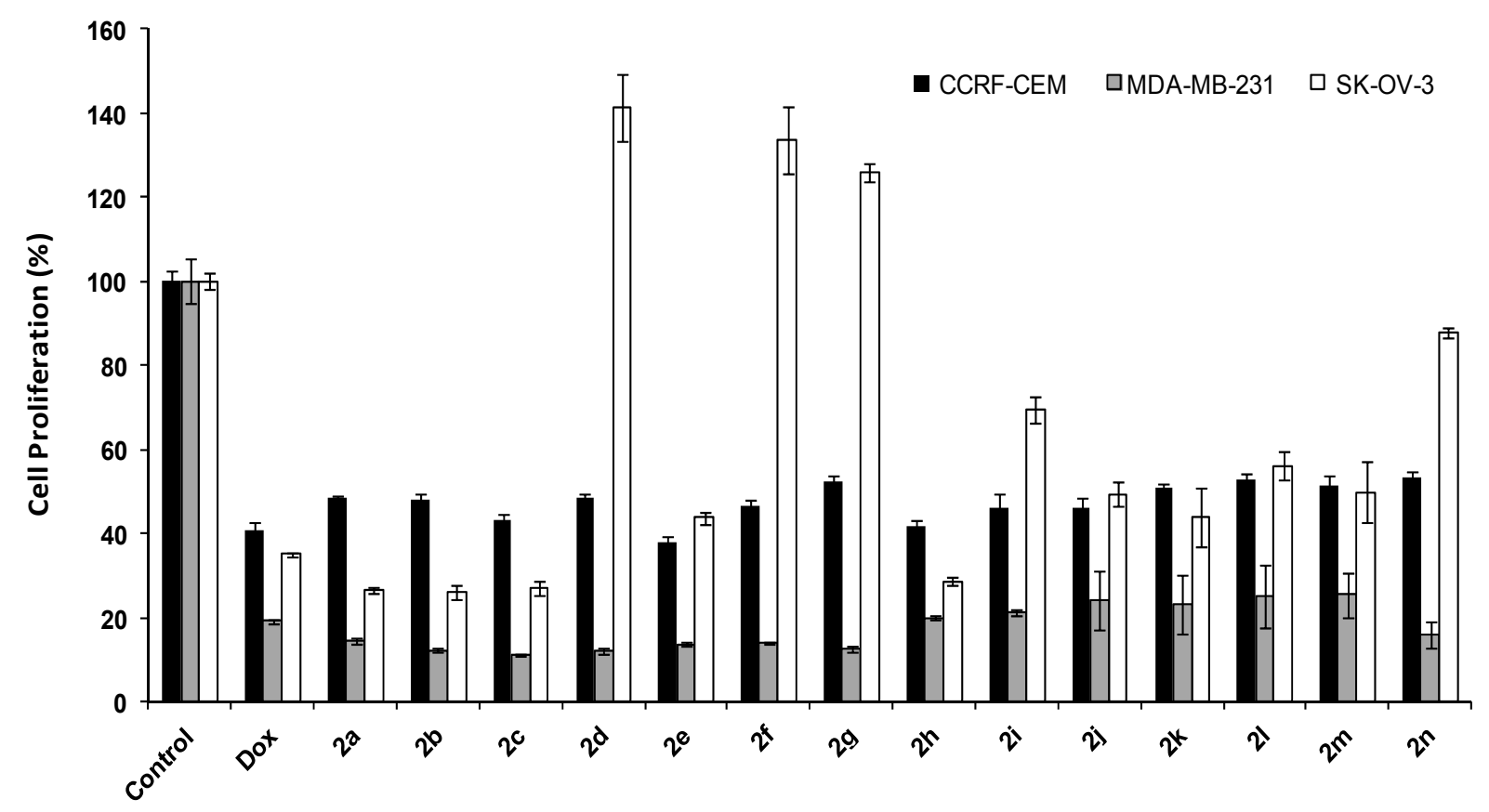

Figure 2. Antiproliferative activity of $N$-methylspiro-pyrrolidine derivatives $\mathbf{4 a}-\mathbf{n}$.

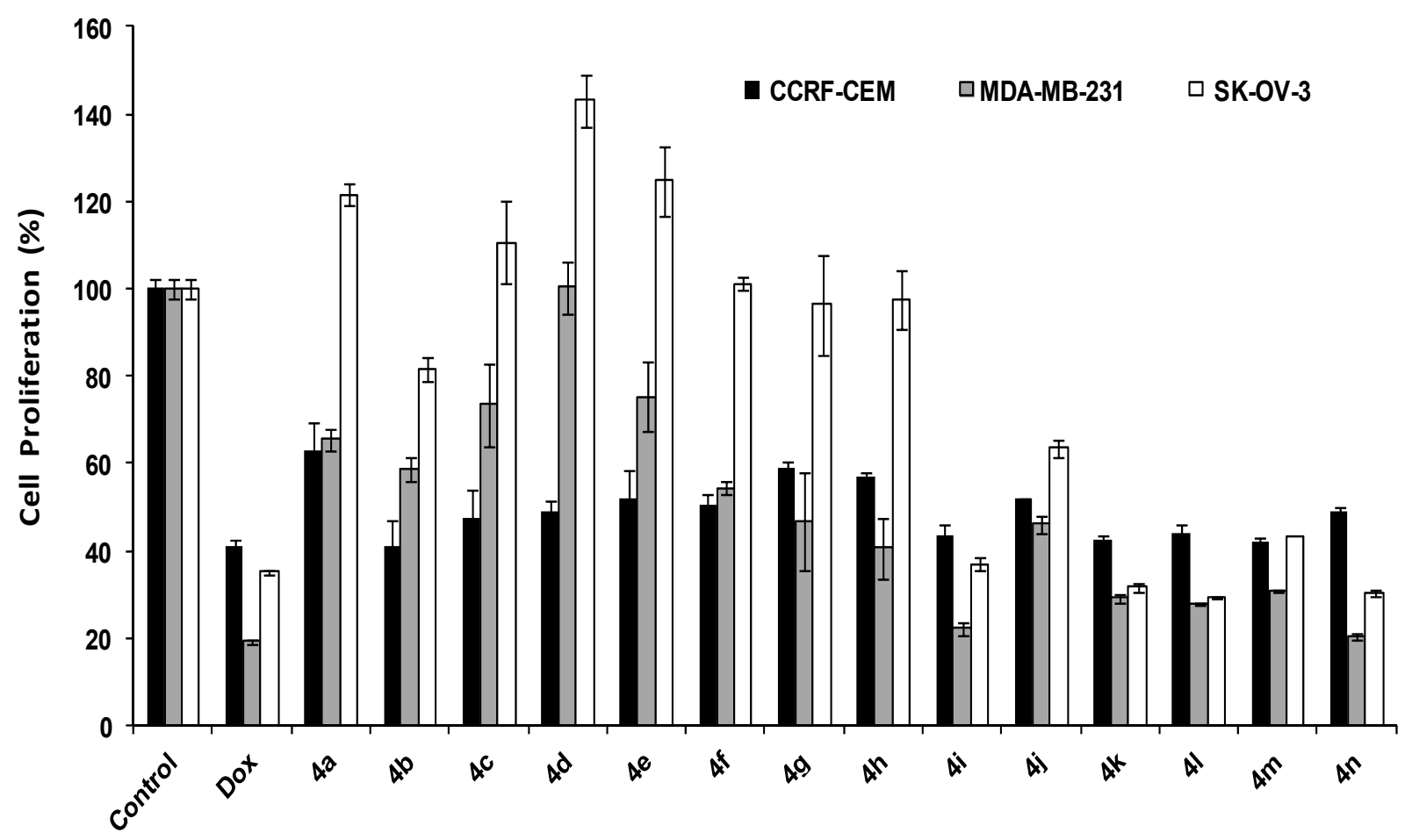


$N$ - $\alpha$-Phenyl substituted spiro-pyrrolidines derivatives $\mathbf{5 a - n}$ were evaluated for their antiproliferative potency against SK-OV-3, MDA-MB-231, and CCRF-CEM cells. All compounds showed higher antiproliferative potency in MDA-MB-231 than other cancer cell lines (Figure 3).

Figure 3. Antiproliferative activity of $N$ - $\alpha$-phenyl substituted spiro-pyrrolidines derivatives $\mathbf{5 a}-\mathbf{n}$.

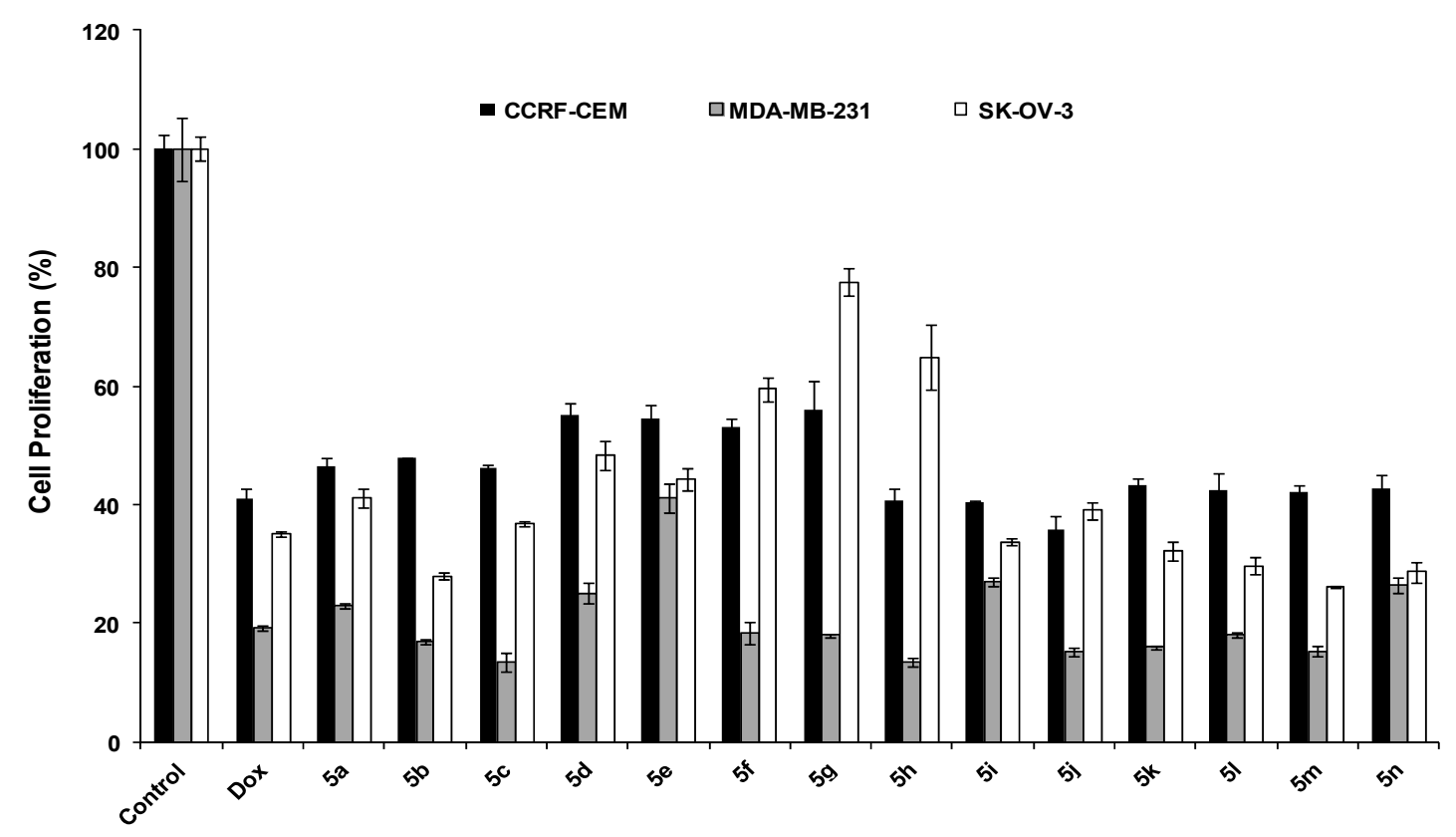

The majority of compounds showed modest to modest antiproliferative activity in MDA-MB-231 cells by inhibiting the proliferation in a range of $59 \%$ to $87 \%$. The potency of compound $\mathbf{5 g}$ was found to be cell-specific since this compound inhibited the proliferation of MDA-MB-231, CCRF-CEM, and SK-OV-3 by $82 \%, 44 \%$, and $22 \%$, respectively. In general, the $N$ - $\alpha$-phenyl substituted spiro-pyrrolidines derivatives 5a-n showed higher antiproliferative activity when compared with the corresponding $N$-methyl spiro-pyrrolidine derivatives $\mathbf{4 a}-\mathbf{n}$. For instance, 2-chlorosubstituted $4 \mathbf{d}$ did not inhibit the proliferation of SK-OV-3 and MDA-MB-231 cells. However, after the replacement of hydrogen with a phenyl ring at position 5 in the corresponding 2-chlorosubstituted compound $\mathbf{5 d}$, the antiproliferative potency elevated significantly by $52 \%, 75 \%$ in SK-OV-3 and MDA-MB-231, respectively, suggesting that the presence of phenyl group contributes to the improvement of the antiproliferative potency of the compound. Finally, a class of spiro-pyrrolizines derivatives was examined for their antiproliferative activity against SK-OV-3, MDA-MB-231, and CCRF-CEM cells (Figure 4).

A number of derivatives including $\mathbf{6 a}-\mathbf{c}$ and $\mathbf{6 i}-\mathbf{m}$ compounds showed a comparable activity with Dox in all three cell lines. Among all derivatives, compound $\mathbf{6 m}$ inhibited the proliferation of CCRF-CEM cells by $64 \%$. Similarly, compound 6a inhibited MDA-MB-231 proliferation by $87 \%$. However, compound $\mathbf{6 b}$ exhibited higher activity in SK-OV-3 cells by inhibiting their growth up to $74 \%$, respectively. The antiproliferative activity of compounds $\mathbf{6 f}, \mathbf{6 h}$ and $\mathbf{6 n}$ were decreased significantly when compared to their corresponding compounds $\mathbf{5 f}, \mathbf{5 h}$ and $\mathbf{5 n}$. The other spiro-pyrrolizines derivatives in this class showed comparable or higher antiproliferative activity when compared with spiro-pyrrolidines derivatives, suggesting that the less rigidity of the chemical structure contributes possibly 
to their antiproliferative activity. Compounds $6 \mathbf{6}$ and $\mathbf{6 b}$ exhibited $\mathrm{IC}_{50}$ values of 25.2 and $3.6 \mu \mathrm{M}$ in CCRF-CEM cells and 38.9 and $35.8 \mu \mathrm{M}$ in SK-OV-3 cells after $72 \mathrm{~h}$ incubation.

Figure 4. Antiproliferative activity of $\mathbf{6 a}-\mathbf{n}$.

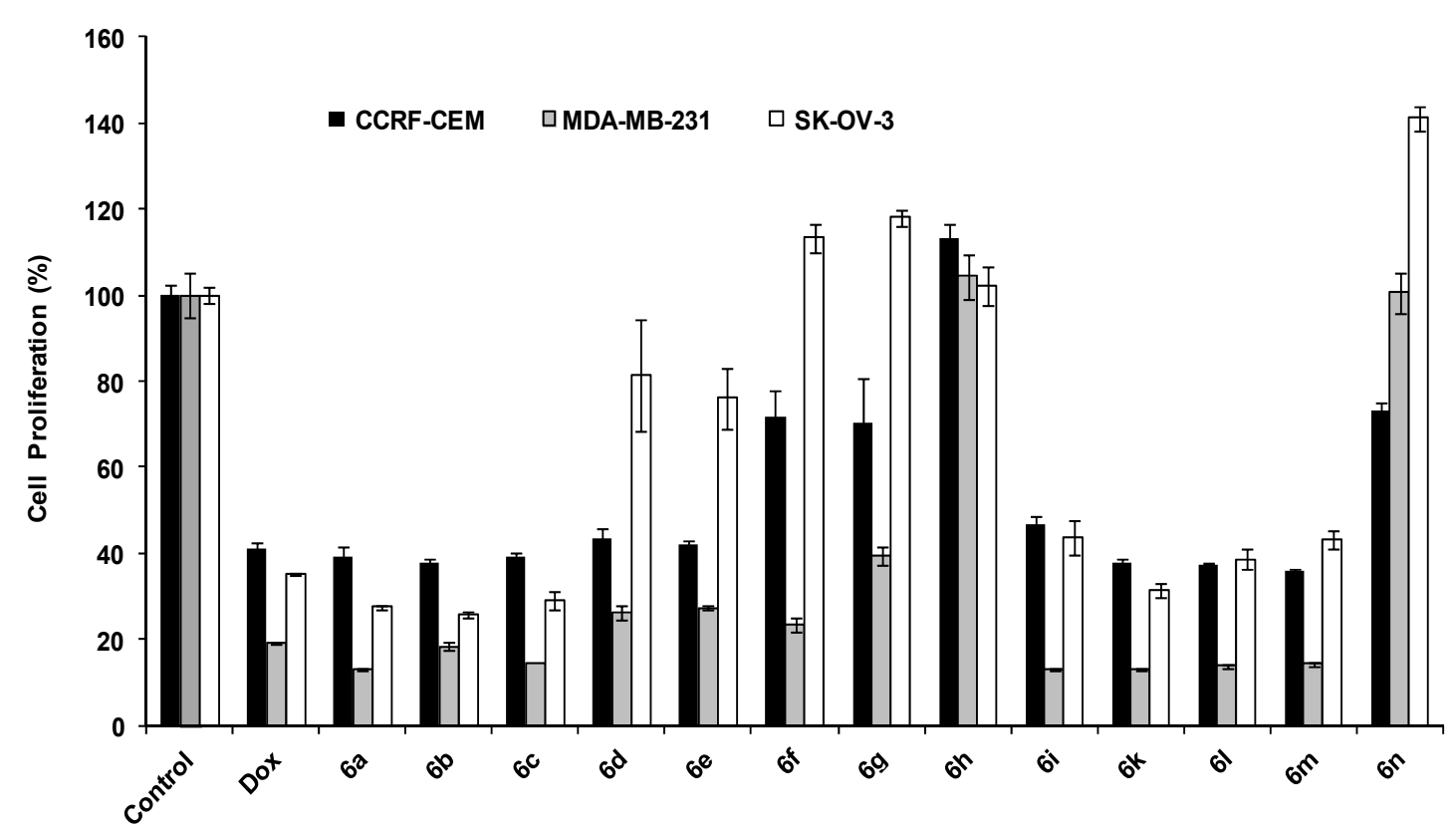

\section{Experimental}

\subsection{General Methods}

The melting points were measured using open capillary tubes and are uncorrected. ${ }^{1} \mathrm{H},{ }^{13} \mathrm{C}$ and two-dimensional NMR spectra were recorded on a Bruker 500, 400 and $300 \mathrm{MHz}$ instruments in $\mathrm{CDCl}_{3}, \mathrm{MeOD}$, and DMSO using TMS as internal standard. Chemical shifts are given in parts per million (-scale) and the coupling constants are given in Hertz. IR spectra were recorded on a JASCO FT IR instrument (KBr pellets). Elemental analyses were performed on a Perkin Elmer 2400 Series II Elemental CHNS analyzer. Column chromatography was performed on silica gel (230-400 mesh) using petroleum ether-ethyl acetate as eluents.

\subsection{General Procedure for the Synthesis of 3,5-bis[(E)-Arylmethylidene]tetrahydro-4(1H)-pyridinones 2}

Following the literature reported procedure by Dimmock et al., an appropriate aryl aldehyde ( $2 \mathrm{mmol})$ was added to a suspension of 4-piperidone hydrochloride monohydrate $(1 \mathrm{mmol})$ in acetic acid $(40 \mathrm{~mL})$. Dry hydrogen chloride was passed through this mixture for 30 min during which time a clear solution was obtained and the stirring continued for $24 \mathrm{~h}$. The precipitate obtained was collected and added to a mixture of saturated aqueous potassium carbonate solution and acetone. The resultant mixture was stirred for $30 \mathrm{~min}$, the free base collected was washed with water and dried and crystalized with ethyl acetate to afford $\mathbf{2}$ in good yield. 
3.3. General Procedure for the Synthesis of 1-Methyl-4-(aryl)pyrrolo-(spiro[2.3"]oxindole)-spiro[3.3']5'(arylmethylidene)-piperidin-4'-ones 4

A mixture of 3,5-bis[(E)-arylmethylidene $]$ tetrahydro-4(1H)-pyridinone (1 mmol), isatin (1.1 mmol), and sarcosine $(1.1 \mathrm{mmol})$ were dissolved in methanol $(5 \mathrm{~mL})$ and heated under reflux for $1 \mathrm{~h}$. After completion of the reaction as evident from TLC, the mixture was poured into water $(50 \mathrm{~mL})$. The precipitated solid was filtered and washed with water to obtain the corresponding product $\mathbf{4}$ in good yield.

\subsection{Spectral Data}

1-Methyl-4-(phenyl)pyrrolo-(spiro[2.3"]oxindole)-spiro[3.3']-5'-(phenylmethylidene)-piperidin-4'-one (4a). Obtained as a pale yellow solid, $(0.150 \mathrm{~g}, 92 \%)$; $\mathrm{mp}=169-171^{\circ} \mathrm{C}$; IR $(\mathrm{KBr}): 1604,1620,1703$, $3407 \mathrm{~cm}^{-1}$; ${ }^{1} \mathrm{H}-\mathrm{NMR}\left(300 \mathrm{MHz}, \mathrm{CDCl}_{3}\right): \delta_{\mathrm{H}} 2.05\left(\mathrm{~d}, 1 \mathrm{H}, J=13.2 \mathrm{~Hz}, 2^{\prime}-\mathrm{CH}_{2}\right), 2.14\left(\mathrm{~s}, 1 \mathrm{H}, \mathrm{N}-\mathrm{CH}_{3}\right)$, 3.35 (dd, $\left.1 \mathrm{H}, J=7.2,7.2 \mathrm{~Hz}, 5-\mathrm{CH}_{2}\right), 3.50-3.58\left(\mathrm{~m}, 2 \mathrm{H}, 6{ }^{\prime}-\mathrm{CH}_{2}\right), 3.64$ (d, $\left.1 \mathrm{H}, J=13.2 \mathrm{~Hz}, 2^{\prime}-\mathrm{CH}_{2}\right)$, $3.94\left(\mathrm{dd}, 1 \mathrm{H}, J=9.0,8.7 \mathrm{~Hz}, 5-\mathrm{CH}_{2}\right), 4.85(\mathrm{dd}, 1 \mathrm{H}, J=7.2,7.2 \mathrm{~Hz}, 4-\mathrm{CH}), 6.66-7.43(\mathrm{~m}, 15 \mathrm{H}, \mathrm{Ar}-\mathrm{H})$, $8.41(\mathrm{~s}, 1 \mathrm{H}, 1 "-\mathrm{NH}) .{ }^{13} \mathrm{C}-\mathrm{NMR}\left(75 \mathrm{MHz}, \mathrm{CDCl}_{3}\right): \delta_{\mathrm{C}} 35.07,46.43,48.66,50.38,57.35,66.75,76.29$, $109.46,122.55,127.22,127.99,128.29,128.59$, 128.66, 128.97, 129.26, 130.01, 130.24, 135.16, 135.63, 137.75, 138.97, 142.15, 178.69, 199.98. Anal. calcd for $\mathrm{C}_{29} \mathrm{H}_{27} \mathrm{~N}_{3} \mathrm{O}_{2}: \mathrm{C}, 77.48 ; \mathrm{H}, 6.05 ; \mathrm{N}$, 9.35; found: C, 77.34; H, 6.23; N, 9.28.

1-Methyl-4-(2-methylphenyl)pyrrolo-(spiro[2.3"]oxindole)-spiro[3.3']-5'-(2-methylphenylmethylidene) piperidin-4'-one (4b). Obtained as a pale yellow solid, (0.140 g, 90\%); mp $=163-164{ }^{\circ} \mathrm{C}$; IR $(\mathrm{KBr})$ : 1602, 1615, 1711, $3405 \mathrm{~cm}^{-1} ;{ }^{1} \mathrm{H}-\mathrm{NMR}\left(400 \mathrm{MHz}, \mathrm{CDCl}_{3}\right): \delta_{\mathrm{H}} 2.06-2.09\left(\mathrm{~m}, 1 \mathrm{H}, 2^{\prime}-\mathrm{CH}_{2}\right), 2.15(\mathrm{~s}, 3 \mathrm{H}$, $\left.\mathrm{N}-\mathrm{CH}_{3}\right), 2.17\left(\mathrm{~s}, 3 \mathrm{H}, \mathrm{CH}_{3}\right), 2.32\left(\mathrm{~s}, 3 \mathrm{H}, \mathrm{CH}_{3}\right), 3.25-3.56\left(\mathrm{~m}, 4 \mathrm{H}, 5-\mathrm{CH}_{2}, 6{ }^{\prime}-\mathrm{CH}_{2}\right.$ and 2'- $\left.\mathrm{CH}_{2}\right), 4.00$ (t, $\left.1 \mathrm{H}, J=9.2 \mathrm{~Hz}, 5-\mathrm{CH}_{2}\right), 4.98$ (t, $\left.1 \mathrm{H}, J=8.0 \mathrm{~Hz}, 4-\mathrm{CH}\right), 6.72-7.57$ (m, 11H, Ar-H), $7.70(\mathrm{~d}, 1 \mathrm{H}, J=6.8 \mathrm{~Hz}$, $\mathrm{Ar}-\mathrm{H}), 7.83(\mathrm{~d}, 1 \mathrm{H}, J=8.0 \mathrm{~Hz}, \mathrm{Ar}-\mathrm{H}), 8.23(\mathrm{~s}, 1 \mathrm{H}, 1 "-\mathrm{NH}) .{ }^{13} \mathrm{C}-\mathrm{NMR}\left(100 \mathrm{MHz}, \mathrm{CDCl}_{3}\right): \delta_{\mathrm{C}} 20.44$, 21.55, 35.06, 42.46, 48.66, 51.44, 58.81, 64.72, 76.04, 109.60, 122.98, 125.69, 126.21, 126.99, 128.38, $128.85,128.99,129.18,129.74,129.83,130.47,130.56,130.61,131.15,134.12,134.54,137.53$, 138.09, 142.30, 178.21, 199.75. Anal. calcd for $\mathrm{C}_{31} \mathrm{H}_{31} \mathrm{~N}_{3} \mathrm{O}_{2}$ : C, 77.96; $\mathrm{H}, 6.54 ; \mathrm{N}, 8.80$; found: C, $77.81 ; \mathrm{H}, 6.65 ; \mathrm{N}, 8.69$.

1-Methyl-4-(2-methoxyphenyl)pyrrolo-(spiro[2.3"] oxindole)-spiro[3.3']-5'-(2-methoxyphenylmethylid ene)piperidin-4'-one (4c). Obtained as a white solid, $(0.130 \mathrm{~g}, 86 \%) ; \mathrm{mp}=159-160{ }^{\circ} \mathrm{C}$; $\mathrm{IR}(\mathrm{KBr})$ : 1599, 1617, 1705, $3410 \mathrm{~cm}^{-1}$; ${ }^{1} \mathrm{H}-\mathrm{NMR}\left(300 \mathrm{MHz} \mathrm{CDCl}_{3}\right): \delta_{\mathrm{H}} 2.15\left(\mathrm{~s}, 3 \mathrm{H}, \mathrm{N}-\mathrm{CH}_{3}\right), 2.30(\mathrm{~d}, 1 \mathrm{H}$, $\left.J=13.8 \mathrm{~Hz}, 2^{\prime}-\mathrm{CH}_{2}\right), 3.24-3.71\left(\mathrm{~m}, 4 \mathrm{H}, 5-\mathrm{CH}_{2}, 6{ }^{\prime}-\mathrm{CH}_{2}\right.$ and $\left.2^{\prime}-\mathrm{CH}_{2}\right), 3.73\left(\mathrm{~s}, 3 \mathrm{H}, \mathrm{OCH}_{3}\right), 3.81(\mathrm{~s}, 3 \mathrm{H}$, $\left.\mathrm{OCH}_{3}\right), 4.10\left(\mathrm{dd}, 1 \mathrm{H}, J=9.3,9.0 \mathrm{~Hz}, 5-\mathrm{CH}_{2}\right), 4.93(\mathrm{dd}, 1 \mathrm{H}, J=8.1,7.5 \mathrm{~Hz}, 4-\mathrm{CH}), 6.68-7.65$ (m, $13 \mathrm{H}, \mathrm{Ar}-\mathrm{H}), 8.37$ (s, 1H, 1"-NH). ${ }^{13} \mathrm{C}-\mathrm{NMR}\left(75 \mathrm{MHz}, \mathrm{CDCl}_{3}\right): \delta_{\mathrm{C}} 35.28,40.39,48.42,55.07,55.34$, 55.71, 56.28, 64.03, 76.44, 109.66, 110.25, 110.94, 120.18, 120.89,122.50, 122.89, 124.90, 126.47, $127.96,128.72,128.98,129.18,130.48,130.63,133.59,134.32,142.28,158.34,158.48,178.51$, 199.07. Anal. calcd for $\mathrm{C}_{31} \mathrm{H}_{31} \mathrm{~N}_{3} \mathrm{O}_{4}$ : C, 73.06; $\mathrm{H}, 6.13 ; \mathrm{N}, 8.25$; found: $\mathrm{C}, 73.28 ; \mathrm{H}, 6.29 ; \mathrm{N}, 8.32$.

1-Methyl-4-(2-chlorophenyl)pyrrolo-(spiro[2.3"]oxindole)-spiro[3.3']-5'-(2-chlorophenylmethylidene) piperidin-4'-one (4d). Obtained as a white solid, (0.137 g, 91\%); $\mathrm{mp}=168-169{ }^{\circ} \mathrm{C}$; IR (KBr): 1598, 
1615, 1706, $3409 \mathrm{~cm}^{-1} ;{ }^{1} \mathrm{H}-\mathrm{NMR}\left(400 \mathrm{MHz}, \mathrm{CDCl}_{3}\right): \delta_{\mathrm{H}} 2.03\left(\mathrm{~d}, 1 \mathrm{H}, J=14.2 \mathrm{~Hz}, 2^{\prime}-\mathrm{CH}_{2}\right), 2.13$ (s, $\left.3 \mathrm{H}, \mathrm{N}-\mathrm{CH}_{3}\right), 3.25-3.57\left(\mathrm{~m}, 4 \mathrm{H}, 5-\mathrm{CH}_{2}, 6{ }^{\prime}-\mathrm{CH}_{2}\right.$ and $\left.{ }^{\prime}-\mathrm{CH}_{2}\right), 3.99\left(\mathrm{t}, 1 \mathrm{H}, J=8.8 \mathrm{~Hz}, 5-\mathrm{CH}_{2}\right), 5.14(\mathrm{t}$, $1 \mathrm{H}, J=8.8 \mathrm{~Hz}, 4-\mathrm{CH}), 6.72(\mathrm{~d}, 1 \mathrm{H}, J=7.6 \mathrm{~Hz}, \mathrm{Ar}-\mathrm{H}), 6.87-7.31$ (m, 8H, Ar-H), 7.34 (d, 2H, $J=8.0 \mathrm{~Hz}$, Ar-H), $7.64(\mathrm{~s}, 1 \mathrm{H}, \mathrm{C}=\mathrm{CH}), 8.00(\mathrm{~d}, 1 \mathrm{H}, J=8.0 \mathrm{~Hz}, \mathrm{Ar}-\mathrm{H}), 8.31$ (s, 1H, 1"-NH). ${ }^{13} \mathrm{C}-\mathrm{NMR}(100 \mathrm{MHz}$, $\left.\mathrm{CDCl}_{3}\right): \delta_{\mathrm{C}} 35.12,43.14,48.52,50.83,57.97,64.01,77.67,109.62,123.54,126.56,126.83,127.12$, $128.37,128.58,129.32,129.59,129.64,130.10,130.48,131.29,134.06,135.05,135.30,135.61$, 136.27, 137.30, 141.98, 178.20, 198.60. Anal. calcd for $\mathrm{C}_{29} \mathrm{H}_{25} \mathrm{Cl}_{2} \mathrm{~N}_{3} \mathrm{O}_{2}$ : C, 67.19; $\mathrm{H}, 4.86 ; \mathrm{N}, 8.11$; found: C, 67.30; H, 4.70; N, 8.04.

1-Methyl-4-(2-bromophenyl)pyrrolo-(spiro[2.3"]oxindole)-spiro[3.3']-5'-(2-bromophenylmethylidene) piperidin-4'-one (4e). Obtained as a white solid, (0.126 g, 90\%); $\mathrm{mp}=143-144{ }^{\circ} \mathrm{C}$; IR (KBr): 1605 , 1614, 1702, $3412 \mathrm{~cm}^{-1} ;{ }^{1} \mathrm{H}-\mathrm{NMR}\left(400 \mathrm{MHz}, \mathrm{CDCl}_{3}\right): \delta_{\mathrm{H}} 1.99$ (d, $1 \mathrm{H}, J=14.8 \mathrm{~Hz}, 2^{\prime}-\mathrm{CH}_{2}$ ), 2.13 (s, $\left.3 \mathrm{H}, \mathrm{N}-\mathrm{CH}_{3}\right), 3.24-3.57\left(\mathrm{~m}, 4 \mathrm{H}, 5-\mathrm{CH}_{2}, 6^{\prime}-\mathrm{CH}_{2}\right.$ and $\left.2^{\prime}-\mathrm{CH}_{2}\right), 3.96\left(\mathrm{t}, 1 \mathrm{H}, J=8.8 \mathrm{~Hz}, 5-\mathrm{CH}_{2}\right), 5.08$ (t, $1 \mathrm{H}, J=8.4 \mathrm{~Hz}, 4-\mathrm{CH}), 6.74(\mathrm{~d}, 1 \mathrm{H}, J=7.6 \mathrm{~Hz}, \mathrm{Ar}-\mathrm{H}), 6.89$ (d, 1H, $J=7.2 \mathrm{~Hz}, \mathrm{Ar}-\mathrm{H}), 6.98-7.61$ (m, $8 \mathrm{H}, \mathrm{Ar}-\mathrm{H}), 7.65(\mathrm{~s}, 1 \mathrm{H}, \mathrm{C}=\mathrm{CH}), 7.94(\mathrm{t}, 1 \mathrm{H}, J=8.8 \mathrm{~Hz}, \mathrm{Ar}-\mathrm{H}), 8.05(\mathrm{~d}, 1 \mathrm{H}, J=7.6 \mathrm{~Hz}, \mathrm{Ar}-\mathrm{H}), 8.42$ (s, 1H, 1"-NH). ${ }^{13} \mathrm{C}-\mathrm{NMR}\left(100 \mathrm{MHz}, \mathrm{CDCl}_{3}\right): \delta_{\mathrm{C}} 35.10,46.09,48.27,50.78,58.47,63.85,76.14$, $109.68,123.64,125.46,126.81,127.19,127.64,127.70,128.59,128.69,129.33,130.24,130.46$, $131.73,132.95,133.01,133.35,135.85,137.26,139.08,142.05,178.22,198.58$. Anal. calcd for $\mathrm{C}_{29} \mathrm{H}_{25} \mathrm{Br}_{2} \mathrm{~N}_{3} \mathrm{O}_{2}$ : C, 57.35; H, 4.15; N, 6.92; found: C, 57.52; H, 4.01; N, 6.84 .

1-Methyl-4-(2-fluorophenyl)pyrrolo-(spiro[2.3"]oxindole)-spiro[3.3']-5'-(2-fluorophenylmethylidene) piperidin-4'-one (4f). Obtained as a white solid, (0.143 g, 92\%); $\mathrm{mp}=165-166{ }^{\circ} \mathrm{C}$; IR (KBr): 1603 , $1617,1705,3408 \mathrm{~cm}^{-1} ;{ }^{1} \mathrm{H}-\mathrm{NMR}\left(400 \mathrm{MHz}, \mathrm{CDCl}_{3}\right): \delta_{\mathrm{H}} 2.14\left(\mathrm{~s}, 3 \mathrm{H}, \mathrm{N}-\mathrm{CH}_{3}\right), 2.30(\mathrm{~d}, 1 \mathrm{H}, J=13.6 \mathrm{~Hz}$, $\left.2^{\prime}-\mathrm{CH}_{2}\right), 3.27-3.55\left(\mathrm{~m}, 4 \mathrm{H}, 5-\mathrm{CH}_{2}, 6^{\prime}-\mathrm{CH}_{2}\right.$ and 2'- $\left.\mathrm{CH}_{2}\right), 3.98\left(\mathrm{t}, 1 \mathrm{H}, J=9.6 \mathrm{~Hz}, 5-\mathrm{CH}_{2}\right), 5.08(\mathrm{t}, 1 \mathrm{H}$, $J=9.6 \mathrm{~Hz}, 4-\mathrm{CH}), 6.68(\mathrm{~d}, 1 \mathrm{H}, J=7.6 \mathrm{~Hz}, \mathrm{Ar}-\mathrm{H}), 6.83-7.32(\mathrm{~m}, 11 \mathrm{H}, \mathrm{Ar}-\mathrm{H}), 7.76(\mathrm{t}, 1 \mathrm{H}, J=7.2 \mathrm{~Hz}$, $\mathrm{Ar}-\mathrm{H}), 8.01$ (s, $1 \mathrm{H}, 1$ "-NH). ${ }^{13} \mathrm{C}-\mathrm{NMR}\left(100 \mathrm{MHz}, \mathrm{CDCl}_{3}\right): \delta_{\mathrm{C}} 35.07,38.61,48.80,50.68,56.97,65.03$, $76.89,109.42,115.45\left({ }^{2} J_{\mathrm{CF}}=22.6 \mathrm{~Hz}\right), 116.00\left({ }^{2} J_{\mathrm{CF}}=21.8 \mathrm{~Hz}\right), 122.99,123.92,123.96,126.49$, $127.15,128.25,128.59,128.73,129.15,129.30,130.68,130.79,130.87,136.23,141.90,160.68$, 162.23, 178.20, 198.37. Anal. calcd for $\mathrm{C}_{2} \mathrm{H}_{25} \mathrm{~F}_{2} \mathrm{~N}_{3} \mathrm{O}_{2}$ : C, 71.74; H, 5.19; N, 8.65; found: C, 71.95; $\mathrm{H}$, $5.08 ; \mathrm{N}, 8.78$.

1-Methyl-4-(2,4-dichlorophenyl)pyrrolo-(spiro[2.3"] oxindole)-spiro[3.3']-5'-(2,4-dichlorophenylmeth ylidene)piperidin-4'-one (4g). Obtained as a white solid, $(0.127 \mathrm{~g}, 90 \%) ; \mathrm{mp}=171-172{ }^{\circ} \mathrm{C}$; IR $(\mathrm{KBr})$ : 1600, 1619, 1708, $3406 \mathrm{~cm}^{-1}$; ${ }^{1} \mathrm{H}-\mathrm{NMR}\left(300 \mathrm{MHz}, \mathrm{CDCl}_{3}\right): \delta_{\mathrm{H}} 2.11\left(\mathrm{~s}, 3 \mathrm{H}, \mathrm{N}-\mathrm{CH}_{3}\right), 2.22-2.25(\mathrm{~m}$, $\left.1 \mathrm{H}, 2^{\prime}-\mathrm{CH}_{2}\right), 3.27-3.56\left(\mathrm{~m}, 4 \mathrm{H}, 6^{\prime}-\mathrm{CH}_{2}, 2^{\prime}-\mathrm{CH}_{2}\right.$ and 5- $\left.\mathrm{CH}_{2}\right), 3.91\left(\mathrm{t}, 1 \mathrm{H}, J=9.0 \mathrm{~Hz}, 5-\mathrm{CH}_{2}\right), 5.07$ (t, $1 \mathrm{H}, J=8.7 \mathrm{~Hz}, 4-\mathrm{CH}), 6.69-7.44(\mathrm{~m}, 8 \mathrm{H}, \mathrm{Ar}-\mathrm{H}), 7.54$ (s, 1H, Ar-H), $7.86(\mathrm{~d}, 1 \mathrm{H}, J=8.4 \mathrm{~Hz}, \mathrm{Ar}-\mathrm{H})$, $7.95(\mathrm{~d}, 1 \mathrm{H}, J=8.7 \mathrm{~Hz}, \mathrm{Ar}-\mathrm{H}), 8.77(\mathrm{~s}, 1 \mathrm{H}, 1 "-\mathrm{NH}) .{ }^{13} \mathrm{C}-\mathrm{NMR}\left(75 \mathrm{MHz}, \mathrm{CDCl}_{3}\right): \delta_{\mathrm{C}} 35.10,42.65$, $48.11,49.95,57.10,63.92,76.54,109.20,123.47,125.93,126.55,127.03,128.36,129.34,129.48$, $130.06,130.87,132.36,132.54,133.46,133.93,134.41,135.45,135.80,136.04,136.78,142.15$, 178.33, 198.39. Anal. calcd for $\mathrm{C}_{29} \mathrm{H}_{23} \mathrm{Cl}_{4} \mathrm{~N}_{3} \mathrm{O}_{2}$ : C, 59.30; H, 3.95; N, 7.15; found: C, 59.45; H, 3.77; N, 7.01 . 
1-Methyl-4-(3-nitrophenyl)pyrrolo-(spiro[2.3"]oxindole)-spiro[3.3']-5'-(3-nitrophenylmethylidene) piperidin-4'-one (4h). Obtained as a pale yellow solid, $(0.131 \mathrm{~g}, 89 \%) ; \mathrm{mp}=185-186{ }^{\circ} \mathrm{C}$; IR $(\mathrm{KBr})$ : 1599, 1617, 1705, $3408 \mathrm{~cm}^{-1}$; ${ }^{1} \mathrm{H}-\mathrm{NMR}(400 \mathrm{MHz}, \mathrm{MeOH}): \delta_{\mathrm{H}} 2.09-2.13\left(\mathrm{~m}, 1 \mathrm{H}, 2^{\prime}-\mathrm{CH}_{2}\right), 2.17$ (s, $\left.3 \mathrm{H}, \mathrm{N}-\mathrm{CH}_{3}\right), 3.44$ (t, $\left.1 \mathrm{H}, J=7.6 \mathrm{~Hz}, 5-\mathrm{CH}_{2}\right), 3.51-3.60\left(\mathrm{~m}, 2 \mathrm{H}, 6{ }^{\prime}-\mathrm{CH}_{2}\right), 3.64$ (d, 1H, J = $\left.12.8 \mathrm{~Hz}, 2^{\prime}-\mathrm{CH}_{2}\right)$ $3.94\left(\mathrm{t}, 1 \mathrm{H}, J=9.6 \mathrm{~Hz}, 5-\mathrm{CH}_{2}\right), 4.90(\mathrm{dd}, 1 \mathrm{H}, J=7.6,7.2 \mathrm{~Hz}, 4-\mathrm{CH}), 6.74(\mathrm{~d}, 1 \mathrm{H}, J=7.6 \mathrm{~Hz}, \mathrm{Ar}-\mathrm{H})$, 6.92-8.12 (m, 11H, Ar-H), 8.34 (s, 1H, 1"-NH). ${ }^{13} \mathrm{C}-\mathrm{NMR}(100 \mathrm{MHz}, \mathrm{MeOH}): \delta_{\mathrm{C}} 34.92,45.92,48.40$, 50.39, 57.54, 66.71, 76.10, 109.75, 122.50, 122.62, 123.56, 124.40, 124.74, 127.41, 128.20, 129.59, $129.68,129.73,134.98,135.67,136.39,137.03,137.12,141.23,142.22,148.50,148.75,178.18$, 199.03. Anal. calcd for $\mathrm{C}_{29} \mathrm{H}_{25} \mathrm{~N}_{5} \mathrm{O}_{6}$ : C, 64.56; H, 4.67; N, 12.98; found: C, 64.68; H, 4.59; N, 12.85 .

1-Methyl-4-(4-methylphenyl)pyrrolo-(spiro[2.3"]oxindole)-spiro[3.3']-5'-(4-methylphenylmethylidene) piperidin-4'-one (4i). Obtained as a white solid, (0.146 g, 93\%); $\mathrm{mp}=180-181{ }^{\circ} \mathrm{C}$; IR (KBr): 1607 , 1621, 1710, $3412 \mathrm{~cm}^{-1} ;{ }^{1} \mathrm{H}-\mathrm{NMR}\left(400 \mathrm{MHz}, \mathrm{CDCl}_{3}\right): \delta_{\mathrm{H}} 2.14\left(\mathrm{~s}, 3 \mathrm{H}, \mathrm{N}-\mathrm{CH}_{3}\right), 2.20(\mathrm{~d}, 1 \mathrm{H}, J=13.6 \mathrm{~Hz}$, 2'- $\left.\mathrm{CH}_{2}\right), 2.30\left(\mathrm{~s}, 3 \mathrm{H}, \mathrm{CH}_{3}\right), 2.31\left(\mathrm{~s}, 3 \mathrm{H}, \mathrm{CH}_{3}\right), 3.15-3.63\left(\mathrm{~m}, 4 \mathrm{H}, 5-\mathrm{CH}_{2}, 6{ }^{\prime}-\mathrm{CH}_{2}\right.$ and 2'- $\left.\mathrm{CH}_{2}\right), 3.91$ (t, $\left.1 \mathrm{H}, J=9.6 \mathrm{~Hz}, 5-\mathrm{CH}_{2}\right), 4.80(\mathrm{t}, 1 \mathrm{H}, J=9.6 \mathrm{~Hz}, 4-\mathrm{CH}), 6.63-7.32(\mathrm{~m}, 13 \mathrm{H}, \mathrm{Ar}-\mathrm{H}), 8.08(\mathrm{~s}, 1 \mathrm{H}$, $1 "-\mathrm{NH}) .{ }^{13} \mathrm{C}-\mathrm{NMR}\left(100 \mathrm{MHz}, \mathrm{CDCl}_{3}\right): \delta_{\mathrm{C}} 21.43,21.69,35.04,46.18,48.73,50.29,57.51,66.51$, $76.40,109.33,122.55,128.33,129.19,129.54,129.71,129.89,130.16,130.41,132.84,134.38$, 135.83, 136.77, 137.80, 139.27, 142.02, 178.64, 200.02. Anal. calcd for $\mathrm{C}_{31} \mathrm{H}_{31} \mathrm{~N}_{3} \mathrm{O}_{2}$ : C, 77.96; $\mathrm{H}$, $6.54 ; \mathrm{N}, 8.80$; found: C, 78.10; H, 6.46; N, 8.73.

1-Methyl-4-(4-methoxyphenyl)pyrrolo-(spiro[2.3"] oxindole)-spiro[3.3']-5'-(4-methoxyphenylmethylidene) piperidin-4'-one $(\mathbf{4 j})$. Obtained as a pale yellow solid, $(0.129 \mathrm{~g}, 85 \%) ; \mathrm{mp}=187-188{ }^{\circ} \mathrm{C}$; $\mathrm{IR}(\mathrm{KBr})$ : 1600, 1615, 1706, $3410 \mathrm{~cm}^{-1}$; ${ }^{1} \mathrm{H}-\mathrm{NMR}\left(400 \mathrm{MHz}, \mathrm{CDCl}_{3}\right): \delta_{\mathrm{H}} 2.14\left(\mathrm{~s}, 3 \mathrm{H}, \mathrm{N}-\mathrm{CH}_{3}\right), 2.21(\mathrm{~d}, 1 \mathrm{H}$, $\left.J=13.2 \mathrm{~Hz}, 2^{\prime}-\mathrm{CH}_{2}\right), 3.35\left(\mathrm{dd}, 1 \mathrm{H}, J=7.2,7.2 \mathrm{~Hz}, 5-\mathrm{CH}_{2}\right), 3.55-3.76\left(\mathrm{~m}, 2 \mathrm{H}, 6{ }^{\prime}-\mathrm{CH}_{2}\right), 3.77(\mathrm{~s}, 3 \mathrm{H}$, $\left.\mathrm{OCH}_{3}\right), 3.78\left(\mathrm{~s}, 3 \mathrm{H}, \mathrm{OCH}_{3}\right), 3.80-3.91\left(\mathrm{~m}, 2 \mathrm{H}, 5-\mathrm{CH}_{2}\right.$ and $\left.2^{\prime}-\mathrm{CH}_{2}\right), 4.78(\mathrm{dd}, 1 \mathrm{H}, J=7.2,7.2 \mathrm{~Hz}$, 4-CH), 6.65 (d, 1H, $J=7.6 \mathrm{~Hz}, \mathrm{Ar}-\mathrm{H}), 6.77-7.09$ (m, 8H, Ar-H), 7.13 (d, 2H, $J=7.6 \mathrm{~Hz}, \mathrm{Ar}-\mathrm{H}), 7.35$ $(\mathrm{d}, 2 \mathrm{H}, J=8.8 \mathrm{~Hz}, \mathrm{Ar}-\mathrm{H}), 8.27(\mathrm{~s}, 1 \mathrm{H}, 1 "-\mathrm{NH}) .{ }^{13} \mathrm{C}-\mathrm{NMR}\left(100 \mathrm{MHz}, \mathrm{CDCl}_{3}\right): \delta_{\mathrm{C}} 34.61,45.52,48.36$, 49.82, 55.18, 55.22, 57.37, 65.85, 76.12, 108.86, 113.60, 113.74, 122.05, 127.61, 127.90, 128.71, $130.58,131.84,132.37,132.72,137.27,141.66,158.45,159.97,178.22,199.52$. Anal. calcd for $\mathrm{C}_{31} \mathrm{H}_{31} \mathrm{~N}_{3} \mathrm{O}_{4}$ : C, 73.06; H, 6.13; N, 8.25; found: C, 73.17; H, 6.01; N, 8.34.

1-Methyl-4-(4-chlorophenyl)pyrrolo-(spiro[2.3"]oxindole)-spiro[3.3']-5'-(4-chlorophenylmethylidene) piperidin-4'-one (4k). Obtained as a pale yellow solid, $(0.140 \mathrm{~g}, 93 \%) ; \mathrm{mp}=169-170^{\circ} \mathrm{C}$; $\mathrm{IR}(\mathrm{KBr})$ : 1602, 1617, 1709, $3410 \mathrm{~cm}^{-1}$; ${ }^{1} \mathrm{H}-\mathrm{NMR}\left(500 \mathrm{MHz}, \mathrm{CDCl}_{3}\right): \delta_{\mathrm{H}} 2.07-2.10\left(\mathrm{~m}, 1 \mathrm{H}, 2^{\prime}-\mathrm{CH}_{2}\right), 2.13(\mathrm{~s}, 3 \mathrm{H}$, $\left.\mathrm{N}-\mathrm{CH}_{3}\right), 3.34$ (t, $\left.1 \mathrm{H}, J=8.0 \mathrm{~Hz}, 5-\mathrm{CH}_{2}\right), 3.48-3.54\left(\mathrm{~m}, 2 \mathrm{H}, 6{ }^{\prime}-\mathrm{CH}_{2}\right), 3.60$ (d, 1H, $\left.J=13.0 \mathrm{~Hz}, 2^{\prime}-\mathrm{CH}_{2}\right)$, $3.86\left(\mathrm{t}, 1 \mathrm{H}, J=10.0 \mathrm{~Hz}, 5-\mathrm{CH}_{2}\right), 4.79(\mathrm{dd}, 1 \mathrm{H}, J=7.5,7.5 \mathrm{~Hz}, 4-\mathrm{CH}), 6.67$ (d, $\left.1 \mathrm{H}, J=8.0 \mathrm{~Hz}, \mathrm{Ar}-\mathrm{H}\right)$, $6.91(\mathrm{~d}, 2 \mathrm{H}, J=8.0 \mathrm{~Hz}, \mathrm{Ar}-\mathrm{H}), 6.97$ (t, 1H, $J=7.5 \mathrm{~Hz}, \mathrm{Ar}-\mathrm{H}), 7.00(\mathrm{~s}, 1 \mathrm{H}, \mathrm{C}=\mathrm{CH}), 7.07-7.13(\mathrm{~m}, 2 \mathrm{H}$, Ar-H), 7.21-7.28 (m, 4H, Ar-H), 7.35 (d, 2H, $J=8.5 \mathrm{~Hz}, \mathrm{Ar}-\mathrm{H}), 8.45$ (s, 1H, 1"-NH). ${ }^{13} \mathrm{C}-\mathrm{NMR}$ $\left(125 \mathrm{MHz}, \mathrm{CDCl}_{3}\right): \delta_{\mathrm{C}} 34.60,45.32,48.21,49.92,56.99,66.17,75.81,109.17,122.15,127.81,128.42$, $128.53,128.78,129.00,130.97,131.07,132.69,133.50,134.71,134.98,136.16,137.00,141.77$, 178.30, 199.24. Anal. calcd for $\mathrm{C}_{29} \mathrm{H}_{25} \mathrm{Cl}_{2} \mathrm{~N}_{3} \mathrm{O}_{2}$ : C, 67.19; H, 4.86; N, 8.11; found: C, 67.07; H, 4.73; $\mathrm{N}, 8.19$. 
1-Methyl-4-(4-bromophenyl)pyrrolo-(spiro[2.3"]oxindole)-spiro[3.3']-5'-(4-bromophenylmethylidene) piperidin-4'-one (4I). Obtained as a pale yellow solid, $(0.127 \mathrm{~g}, 91 \%) ; \mathrm{mp}=172-173{ }^{\circ} \mathrm{C}$; IR (KBr): 1598, 1619, 1710, $3409 \mathrm{~cm}^{-1}$; ${ }^{1} \mathrm{H}-\mathrm{NMR}(300 \mathrm{MHz}, \mathrm{MeOH}): \delta_{\mathrm{H}} 2.11\left(\mathrm{~s}, 3 \mathrm{H}, \mathrm{N}-\mathrm{CH}_{3}\right), 2.17(\mathrm{~d}, 1 \mathrm{H}$, $\left.J=13.2 \mathrm{~Hz}, 2^{\prime}-\mathrm{CH}_{2}\right), 3.32-3.56\left(\mathrm{~m}, 4 \mathrm{H}, 5-\mathrm{CH}_{2}, 6^{\prime}-\mathrm{CH}_{2}\right.$ and $\left.2^{\prime}-\mathrm{CH}_{2}\right), 3.90(\mathrm{dd}, 1 \mathrm{H}, J=9.0,9.0 \mathrm{~Hz}$, 5- $\left.\mathrm{CH}_{2}\right), 4.64(\mathrm{~s}, 1 \mathrm{H}, 1$ "-NH), $4.76(\mathrm{dd}, 1 \mathrm{H}, J=7.5,7.2 \mathrm{~Hz}, 4-\mathrm{CH}), 6.72(\mathrm{~d}, 1 \mathrm{H}, J=7.8 \mathrm{~Hz}, \mathrm{Ar}-\mathrm{H})$, 6.98-7.18 (m, 6H, Ar-H), 7.34 (d, 2H, $J=8.4 \mathrm{~Hz}, \mathrm{Ar}-\mathrm{H}), 7.45-7.48$ (m, 4H, Ar-H). ${ }^{13} \mathrm{C}-\mathrm{NMR}(75 \mathrm{MHz}$, $\mathrm{MeOH}): \delta_{\mathrm{C}} 33.86,45.84,48.28,50.01,57.10,65.86,76.31,109.55,120.81,121.91,122.96,127.15$, 127.74, 129.36, 131.43, 131.56, 131.69, 131.77, 134.43, 135.74, 136.13, 138.06, 143.25, 178.53, 199.78. Anal. calcd for $\mathrm{C}_{29} \mathrm{H}_{25} \mathrm{Br}_{2} \mathrm{~N}_{3} \mathrm{O}_{2}$ : C, 57.35; H, 4.15; N, 6.92; found: C, 57.48; H, 4.27; N, 6.99.

1-Methyl-4-(4-fluorophenyl)pyrrolo-(spiro[2.3"]oxindole)-spiro[3.3']-5'-(4-fluorophenylmethylidene) piperidin-4'-one (4m). Obtained as a white solid, (0.146 g, 94\%); mp = 174-175 ${ }^{\circ} \mathrm{C}$; IR (KBr): 1601 , 1618, 1709, $3411 \mathrm{~cm}^{-1} ;{ }^{1} \mathrm{H}-\mathrm{NMR}(300 \mathrm{MHz}, \mathrm{MeOH}): \delta_{\mathrm{H}} 2.10\left(\mathrm{~s}, 3 \mathrm{H}, \mathrm{N}-\mathrm{CH}_{3}\right), 2.18(\mathrm{~d}, 1 \mathrm{H}, J=13.2 \mathrm{~Hz}$, 2'- $\left.\mathrm{CH}_{2}\right), 3.26-3.57\left(\mathrm{~m}, 4 \mathrm{H}, 5-\mathrm{CH}_{2}, 6{ }^{\prime}-\mathrm{CH}_{2}\right.$ and 2'- $\left.-\mathrm{CH}_{2}\right), 3.89$ (dd, $\left.1 \mathrm{H}, J=9.3,9.0 \mathrm{~Hz}, 5-\mathrm{CH}_{2}\right), 4.65$ (s, $1 \mathrm{H}, 1 "-\mathrm{NH}), 4.78$ (dd, 1H, $J=7.5,7.2 \mathrm{~Hz}, 4-\mathrm{CH}), 6.73$ (d, 1H, $J=7.5 \mathrm{~Hz}, \mathrm{Ar}-\mathrm{H}), 6.89-7.17$ (m, 11H, Ar-H), 7.39-7.44 (m, 1H, Ar-H). ${ }^{13} \mathrm{C}-\mathrm{NMR}(75 \mathrm{MHz}, \mathrm{MeOH}): \delta_{\mathrm{C}} 33.90,45.73,48.22,50.02,57.40$, 65.75, 76.42, 109.54, $114.64\left({ }^{2} J_{\mathrm{CF}}=21.2 \mathrm{~Hz}\right), 115.30\left({ }^{2} J_{\mathrm{CF}}=21.8 \mathrm{~Hz}\right), 121.93,127.22,127.75$, 129.32, $131.30\left(J_{\mathrm{CF}}=77.3 \mathrm{~Hz}\right), 131.73\left(J_{\mathrm{CF}}=3.3 \mathrm{~Hz}\right), 132.25\left(J_{\mathrm{CF}}=83.3 \mathrm{~Hz}\right), 134.64\left({ }^{2} J_{\mathrm{CF}}=3.2 \mathrm{~Hz}\right)$, 134.87, 136.42, 143.22, $162.32\left({ }^{1} J_{\mathrm{CF}}=242.7 \mathrm{~Hz}\right), 163.14\left({ }^{1} J_{\mathrm{CF}}=247.4 \mathrm{~Hz}\right), 178.58,199.98$. Anal. calcd for $\mathrm{C}_{29} \mathrm{H}_{25} \mathrm{~F}_{2} \mathrm{~N}_{3} \mathrm{O}_{2}$ : C, 71.74; H, 5.19; N, 8.65; found: C, 71.87; H, 5.31; N, 8.59.

1-Methyl-4-(1-naphthyl)pyrrolo-(spiro[2.3"] oxindole)-spiro[3.3']-5'-(1-naphthylmethylidene)piperidin$4^{\prime}$-one (4n). Obtained as a pale yellow solid, (0.132 g, 90\%); $\mathrm{mp}=160-161{ }^{\circ} \mathrm{C}$; IR (KBr): 1698, 1620, 1706, $3410 \mathrm{~cm}^{-1}$; ${ }^{1} \mathrm{H}-\mathrm{NMR}(300 \mathrm{MHz}, \mathrm{DMSO}): \delta_{\mathrm{H}} 1.66\left(\mathrm{~d}, 1 \mathrm{H}, J=12.6 \mathrm{~Hz}, 2^{\prime}-\mathrm{CH}_{2}\right), 2.00(\mathrm{~s}, 3 \mathrm{H}$, $\left.\mathrm{N}-\mathrm{CH}_{3}\right), 3.07\left(\mathrm{~d}, 1 \mathrm{H}, J=15.8 \mathrm{~Hz}, 6{ }^{\prime}-\mathrm{CH}_{2}\right), 3.19\left(\mathrm{~d}, 1 \mathrm{H}, J=15.8 \mathrm{~Hz}, 6{ }^{\prime}-\mathrm{CH}_{2}\right), 3.35(\mathrm{t}, 1 \mathrm{H}$, $\left.J=7.8 \mathrm{~Hz}, 5-\mathrm{CH}_{2}\right), 3.55\left(\mathrm{~d}, 1 \mathrm{H}, J=12.6 \mathrm{~Hz}, 2^{\prime}-\mathrm{CH}_{2}\right), 4.05\left(\mathrm{t}, 1 \mathrm{H}, J=9.3 \mathrm{~Hz}, 5-\mathrm{CH}_{2}\right), 5.50(\mathrm{t}, 1 \mathrm{H}$, $J=8.4 \mathrm{~Hz}, 4-\mathrm{CH}), 6.66(\mathrm{~d}, 1 \mathrm{H}, J=6.6 \mathrm{~Hz}, \mathrm{Ar}-\mathrm{H}), 7.02-7.96(\mathrm{~m}, 17 \mathrm{H}, \mathrm{Ar}-\mathrm{H}), 8.12(\mathrm{~d}, 1 \mathrm{H}, J=8.7 \mathrm{~Hz}$, $\mathrm{Ar}-\mathrm{H}), 10.46$ (s, 1H, 1"-NH). ${ }^{13} \mathrm{C}-\mathrm{NMR}$ (75 MHz, DMSO): $\delta_{\mathrm{C}} 34.95,40.63,49.23,51.52,58.72$, 64.93, 76.59, 109.95, 122.19, 124.48, 125.49, 125.89, 126.17, 126.33, 127.12, 127.32, 127.47, 127.61, $127.79,128.03,129.23,129.36,129.56,129.74,129.80,131.64,132.54,133.63,133.74,134.37$, 135.14, 135.84, 137.0, 144.41, 177.57, 199.76. Anal. calcd for $\mathrm{C}_{37} \mathrm{H}_{31} \mathrm{~N}_{3} \mathrm{O}_{2}: \mathrm{C}, 80.85 ; \mathrm{H}, 5.68 ; \mathrm{N}, 7.64$; found: C, 80.96; H, 5.82; N, 7.55.

4,5-Diphenylpyrrolo(spiro[2.3']-oxindole)-spiro-[3.3']-5'-(phenylmethylidene)piperidin-4'-one

(5a). Obtained as a white solid, (0.170 g, 93\%); mp = 162-163 ${ }^{\circ} \mathrm{C}$; IR (KBr): 1593, 1613, 1698, 3179, $3344 \mathrm{~cm}^{-1}$; ${ }^{1} \mathrm{H}-\mathrm{NMR}\left(500 \mathrm{MHz}, \mathrm{CDCl}_{3}\right): \delta_{\mathrm{H}} 2.31\left(\mathrm{~d}, 1 \mathrm{H}, J=13.0 \mathrm{~Hz}, 2^{\prime}-\mathrm{CH}_{2}\right), 3.52(\mathrm{dd}, 1 \mathrm{H}, J=14.5$, $\left.2.5 \mathrm{~Hz}, 6{ }^{\prime}-\mathrm{CH}_{2}\right), 3.64\left(\mathrm{~d}, 1 \mathrm{H}, J=15.0 \mathrm{~Hz}, 6^{\prime}-\mathrm{CH}_{2}\right), 3.77\left(\mathrm{dd}, 1 \mathrm{H}, J=13.0,1.0 \mathrm{~Hz}, 2^{\prime}-\mathrm{CH}_{2}\right), 4.73(\mathrm{~d}$, $1 \mathrm{H}, J=11.0 \mathrm{~Hz}, 4-\mathrm{CH}), 5.43(\mathrm{~d}, 1 \mathrm{H}, J=11.0 \mathrm{~Hz}, 5-\mathrm{CH}), 6.67(\mathrm{~d}, 1 \mathrm{H}, J=7.5 \mathrm{~Hz}, \mathrm{Ar}-\mathrm{H}), 6.98-7.04$ (m, 4H, Ar-H), 7.12-7.28 (m, 11H, Ar-H), 7.41 (d, 2H, $J=7.0 \mathrm{~Hz}, \mathrm{Ar}-\mathrm{H}), 7.53$ (d, 2H, $J=7.5 \mathrm{~Hz}$, $\mathrm{Ar}-\mathrm{H}), 7.99$ (s, 1H, 1"-NH). ${ }^{13} \mathrm{C}-\mathrm{NMR}\left(125 \mathrm{MHz}, \mathrm{CDCl}_{3}\right): \delta_{\mathrm{C}} 48.19,49.74,56.85,64.24,67.34,71.82$, $109.21,122.20,126.85,127.02,127.57,127.66,128.25,128.33,128.70,128.99,129.21,129.89$, 
129.93, 134.86, 135.12, 137.09, 137.38, 140.74, 141.00, 180.91, 200.14. Anal. calcd for $\mathrm{C}_{34} \mathrm{H}_{29} \mathrm{~N}_{3} \mathrm{O}_{2}$ : C, 79.82; H, 5.71; N, 8.21; found: C, 79.70; H, 5.85; N, 8.15.

4-(2-Methylphenyl)-5-phenylpyrrolo(spiro[2.3"]oxindole)spiro[3.3']-5'-(2-methylphenylmethylidene) piperidin-4'-one (5b). Obtained as a pale yellow solid, $(0.160 \mathrm{~g}, 90 \%) ; \mathrm{mp}=150-151{ }^{\circ} \mathrm{C}$; IR $(\mathrm{KBr})$ : 1595, 1618, 1697, 3168, $3340 \mathrm{~cm}^{-1}$; ${ }^{1} \mathrm{H}-\mathrm{NMR}\left(300 \mathrm{MHz}, \mathrm{CDCl}_{3}\right): \delta_{\mathrm{H}} 2.11\left(\mathrm{~s}, 1 \mathrm{H}, \mathrm{CH}_{3}\right), 2.20(\mathrm{~s}, 1 \mathrm{H}$, $\left.\mathrm{CH}_{3}\right), 2.27-2.32\left(\mathrm{~m}, 1 \mathrm{H}, 2^{\prime}-\mathrm{CH}_{2}\right), 3.41\left(\mathrm{~d}, 1 \mathrm{H}, J=15.3 \mathrm{~Hz}, 6{ }^{\prime}-\mathrm{CH}_{2}\right), 3.51(\mathrm{dd}, 1 \mathrm{H}, J=15.3,2.4 \mathrm{~Hz}$, 6'- $\left.\mathrm{CH}_{2}\right), 3.58\left(\mathrm{~d}, 1 \mathrm{H}, J=13.2 \mathrm{~Hz}, 2^{\prime}-\mathrm{CH}_{2}\right), 4.90(\mathrm{~d}, 1 \mathrm{H}, J=9.9 \mathrm{~Hz}, 4-\mathrm{CH}), 5.54(\mathrm{~d}, 1 \mathrm{H}, J=9.9 \mathrm{~Hz}$, 5-CH), 6.73 (d, 1H, $J=7.5 \mathrm{~Hz}, \operatorname{Ar}-\mathrm{H}), 6.82$ (d, 1H, $J=7.5 \mathrm{~Hz}, \operatorname{Ar}-\mathrm{H}), 6.92-7.55$ (m, 15H, Ar-H), $7.63(\mathrm{~s}, 1 \mathrm{H}, \mathrm{C}=\mathrm{CH}), 8.42(\mathrm{~s}, 1 \mathrm{H}, 1 "-\mathrm{NH}) .{ }^{13} \mathrm{C}-\mathrm{NMR}\left(75 \mathrm{MHz}, \mathrm{CDCl}_{3}\right): \delta_{\mathrm{C}} 20.49,21.44,48.43,51.42$, $54.54,65.44,66.53,74.25,109.94,122.91,125.80,125.98,126.29,126.98,127.83,127.91,128.81$, $128.94,129.42,129.64,130.58,130.78,134.36,134.54,135.46,135.60,136.82,137.44,138.21$, 138.31, 138.63, 141.79, 180.90, 201.06. Anal. calcd for $\mathrm{C}_{36} \mathrm{H}_{33} \mathrm{~N}_{3} \mathrm{O}_{2}$ : C, 80.12; H, 6.16; N, 7.79; found: C, 80.28; H, 6.27; N, 7.70.

4-(2-Methoxyphenyl)-5-phenylpyrrolo(spiro[2.3"] oxindole)spiro[3.3']-5'-(2-methoxyphenylmethylidene) piperidin-4'-one (5c). Obtained as a pale yellow solid, $(0.144 \mathrm{~g}, 85 \%) ; \mathrm{mp}=155-156{ }^{\circ} \mathrm{C}$; IR $(\mathrm{KBr})$ : 1597, 1614, 1695, 3173, $3342 \mathrm{~cm}^{-1}$; ${ }^{1} \mathrm{H}-\mathrm{NMR}\left(300 \mathrm{MHz}, \mathrm{CDCl}_{3}\right): \delta_{\mathrm{H}} 2.43\left(\mathrm{~d}, 1 \mathrm{H}, J=13.8 \mathrm{~Hz}, 2^{\prime}-\mathrm{CH}_{2}\right.$ ), 3.26-3.62 (m, 3H, 6'- $\mathrm{CH}_{2}$ and ''- $\left.\mathrm{CH}_{2}\right), 3.65\left(\mathrm{~s}, 3 \mathrm{H}, \mathrm{OCH}_{3}\right), 3.83\left(\mathrm{~s}, 3 \mathrm{H}, \mathrm{OCH}_{3}\right), 4.89(\mathrm{~d}, 1 \mathrm{H}, J=9.9 \mathrm{~Hz}$, 4-CH), 5.74 (d, 1H, $J=9.9 \mathrm{~Hz}, 5-\mathrm{CH}), 6.67-7.86$ (m, 18H, Ar-H and C=CH), 8.02 (s, 1H, 1"-NH). ${ }^{13} \mathrm{C}-\mathrm{NMR}\left(75 \mathrm{MHz}, \mathrm{CDCl}_{3}\right): \delta_{\mathrm{C}} 48.50,49.76,54.32,55.41,55.80,63.89,66.56,74.29,110.36,111.05$, $111.12,120.31,120.51,121.09,122.83,124.72$, 127.33, 127.88, 128.07, 128.31, 128.85, 129.29, $130.53,130.88,131.03,133.42,141.81,158.23,158.76,180.01,201.03$. Anal. calcd for $\mathrm{C}_{36} \mathrm{H}_{33} \mathrm{~N}_{3} \mathrm{O}_{4}$ : C, 75.64; H, 5.82; N, 7.35; found: C, 75.50; H, 5.97; N, 7.18.

4-(2-Chlorophenyl)-5-phenylpyrrolo(spiro[2.3"]oxindole)spiro[3.3']-5'-(2-chlorophenylmethylidene) piperidin-4'-one (5d). Obtained as a white solid, (0.155 g, 92\%); $\mathrm{mp}=151-152{ }^{\circ} \mathrm{C}$; IR (KBr): 1590, 1617, 1692, 3175, $3340 \mathrm{~cm}^{-1}$; ${ }^{1} \mathrm{H}-\mathrm{NMR}\left(300 \mathrm{MHz}, \mathrm{CDCl}_{3}\right): \delta_{\mathrm{H}} 1.97$ (br s, $\left.1 \mathrm{H}, \mathrm{NH}\right), 2.41(\mathrm{~d}, 1 \mathrm{H}$, $\left.J=13.8 \mathrm{~Hz}, 2^{\prime}-\mathrm{CH}_{2}\right), 3.27\left(\mathrm{~d}, 1 \mathrm{H}, J=13.8 \mathrm{~Hz}, 2^{\prime}-\mathrm{CH}_{2}\right), 3.42\left(\mathrm{~d}, 1 \mathrm{H}, J=15.6 \mathrm{~Hz}, 6{ }^{\prime}-\mathrm{CH}_{2}\right), 3.61(\mathrm{~d}$, $\left.1 \mathrm{H}, J=15.6 \mathrm{~Hz}, 6^{\prime}-\mathrm{CH}_{2}\right), 5.11(\mathrm{~d}, 1 \mathrm{H}, J=9.0 \mathrm{~Hz}, 4-\mathrm{CH}), 5.66(\mathrm{~d}, 1 \mathrm{H}, J=9.0 \mathrm{~Hz}, 5-\mathrm{CH}), 6.69(\mathrm{~d}, 1 \mathrm{H}$, $J=7.5 \mathrm{~Hz}, \mathrm{Ar}-\mathrm{H}), 6.97-7.39(\mathrm{~m}, 12 \mathrm{H}, \mathrm{Ar}-\mathrm{H}), 7.58-7.66(\mathrm{~m}, 3 \mathrm{H}, \mathrm{Ar}-\mathrm{H}), 7.84(\mathrm{~s}, 1 \mathrm{H}, \mathrm{C}=\mathrm{CH}), 8.15(\mathrm{~d}$, $1 \mathrm{H}, J=7.2 \mathrm{~Hz}, \mathrm{Ar}-\mathrm{H}), 8.68(\mathrm{~s}, 1 \mathrm{H}, 1 "-\mathrm{NH}) .{ }^{13} \mathrm{C}-\mathrm{NMR}\left(75 \mathrm{MHz}, \mathrm{CDCl}_{3}\right): \delta_{\mathrm{C}} 48.52,50.71,55.41$, $64.74,65.74,75.18,109.92,123.44,126.66,127.17,127.29,127.72,128.12,128.18,128.47,129.00$, $129.51,129.71,130.19,130.32,130.52,131.09,133.87,135.11,135.33,135.58,136.52,136.70$, 141.22, 141.64, 179.14, 200.63. Anal. calcd for $\mathrm{C}_{34} \mathrm{H}_{27} \mathrm{Cl}_{2} \mathrm{~N}_{3} \mathrm{O}_{2}$ : C, 70.35; H, 4.69; N, 7.24; found: C, $70.47 ; \mathrm{H}, 4.61 ; \mathrm{N}, 7.16$.

4-(2-Bromophenyl)-5-phenylpyrrolo(spiro[2.3"] oxindole)spiro[3.3']-5'-(2-bromophenylmethylidene) piperidin-4'-one (5e). Obtained as a white solid, (0.137 g, 89\%); $\mathrm{mp}=153-154{ }^{\circ} \mathrm{C}$; IR (KBr): 1590 , 1611, 1694, 3184, $3337 \mathrm{~cm}^{-1}$; ${ }^{1} \mathrm{H}-\mathrm{NMR}\left(300 \mathrm{MHz}, \mathrm{CDCl}_{3}\right): \delta_{\mathrm{H}} 1.91$ (br s, $\left.1 \mathrm{H}, \mathrm{NH}\right), 2.45(\mathrm{~d}, 1 \mathrm{H}$, $\left.J=13.8 \mathrm{~Hz}, 2^{\prime}-\mathrm{CH}_{2}\right), 3.23\left(\mathrm{~d}, 1 \mathrm{H}, J=13.8 \mathrm{~Hz}, 2^{\prime}-\mathrm{CH}_{2}\right), 3.40\left(\mathrm{~d}, 1 \mathrm{H}, J=15.6 \mathrm{~Hz}, 6{ }^{\prime}-\mathrm{CH}_{2}\right), 3.62(\mathrm{dd}$, $\left.1 \mathrm{H}, J=15.6,2.1 \mathrm{~Hz}, 6^{\prime}-\mathrm{CH}_{2}\right), 5.06(\mathrm{~d}, 1 \mathrm{H}, J=9.3 \mathrm{~Hz}, 4-\mathrm{CH}), 5.67$ (d, 1H, $\left.J=9.3 \mathrm{~Hz}, 5-\mathrm{CH}\right), 6.71(\mathrm{~d}$, $1 \mathrm{H}, J=7.8 \mathrm{~Hz}, \mathrm{Ar}-\mathrm{H}), 6.95-7.44(\mathrm{~m}, 8 \mathrm{H}, \mathrm{Ar}-\mathrm{H}), 7.48$ (d, 2H, $J=7.5 \mathrm{~Hz}, \mathrm{Ar}-\mathrm{H}), 7.58$ (d, 2H, $J=7.2 \mathrm{~Hz}$, 
Ar-H), 7.67 (d, 2H, $J=7.2 \mathrm{~Hz}, \mathrm{Ar}-\mathrm{H}), 7.84$ (s, 1H, C=CH), 8.21(d, 1H, J = 7.8 Hz, Ar-H), 8.67 (s, 1H, $1 "-\mathrm{NH}) .{ }^{13} \mathrm{C}-\mathrm{NMR}\left(75 \mathrm{MHz}, \mathrm{CDCl}_{3}\right): \delta_{\mathrm{C}} 48.28,50.66,58.56,64.64,66.37,75.47,110.01,123.57$, $125.76,127.16,127.32,127.59,127.93,128.13,128.22,128.54,128.83,129.04,129.55,130.54$, $131.49,133.07,133.45,135.14,135.62,137.38,138.44,141.13,141.68,178.95,200.93$. Anal. calcd for $\mathrm{C}_{34} \mathrm{H}_{27} \mathrm{Br}_{2} \mathrm{~N}_{3} \mathrm{O}_{2}$ : C, 61.00; H, 4.07; N, 6.28; found: C, 61.13; H, 4.26; N, 6.40 .

4-(2-Fluorophenyl)-5-phenylpyrrolo(spiro[2.3"] oxindole)spiro[3.3']-5'-(2-fluorophenylmethylidene) piperidin-4'-one (5f). Obtained as a white solid, (0.158 g, 90\%); $\mathrm{mp}=148-149{ }^{\circ} \mathrm{C}$; IR (KBr): 1592 , 1618, 1694, 3178, $3345 \mathrm{~cm}^{-1}$; ${ }^{1} \mathrm{H}-\mathrm{NMR}\left(300 \mathrm{MHz}, \mathrm{CDCl}_{3}\right): \delta_{\mathrm{H}} 2.20$ (br s, $\left.1 \mathrm{H}, \mathrm{NH}\right), 2.43(\mathrm{~d}, 1 \mathrm{H}$, $\left.J=13.5 \mathrm{~Hz}, 2^{\prime}-\mathrm{CH}_{2}\right), 3.31-3.66\left(\mathrm{~m}, 3 \mathrm{H}, 2^{\prime}-\mathrm{CH}_{2}\right.$ and $\left.6^{\prime}-\mathrm{CH}_{2}\right), 5.00(\mathrm{~d}, 1 \mathrm{H}, J=9.9 \mathrm{~Hz}, 4-\mathrm{CH}), 5.57(\mathrm{~d}$, $1 \mathrm{H}, J=9.9 \mathrm{~Hz}, 5-\mathrm{CH}), 6.68(\mathrm{~d}, 1 \mathrm{H}, J=7.5 \mathrm{~Hz}, \mathrm{Ar}-\mathrm{H}), 6.90-7.63(\mathrm{~m}, 16 \mathrm{H}, \mathrm{Ar}-\mathrm{H}), 7.87(\mathrm{~s}, 1 \mathrm{H}$, $\mathrm{C}=\mathrm{CH}), 8.65$ (s, 1H, 1"-NH). ${ }^{13} \mathrm{C}-\mathrm{NMR}\left(75 \mathrm{MHz}, \mathrm{CDCl}_{3}\right): \delta_{\mathrm{C}} 48.79,50.39,63.10,64.48,65.97,73.65$, $109.92,115.64\left({ }^{2} J_{\mathrm{CF}}=23.3 \mathrm{~Hz}\right), 116.08\left({ }^{2} J_{\mathrm{CF}}=21.7 \mathrm{~Hz}\right), 122.94,123.39,123.57,124.07\left(J_{\mathrm{CF}}=3.0 \mathrm{~Hz}\right)$, $124.48\left(J_{\mathrm{CF}}=3.0 \mathrm{~Hz}\right), 127.28,128.01,128.18,128.31,128.92,129.41,129.56,130.16,130.61$, $130.80,131.16,136.04,140.98,141.59,161.15\left({ }^{1} J_{\mathrm{CF}}=250.6 \mathrm{~Hz}\right), 161.96\left({ }^{1} J_{\mathrm{CF}}=244.1 \mathrm{~Hz}\right), 180.24$, 199.77. Anal. calcd for $\mathrm{C}_{34} \mathrm{H}_{27} \mathrm{~F}_{2} \mathrm{~N}_{3} \mathrm{O}_{2}$ : C, 74.57; H, 4.97; N, 7.67; found: C, 74.45; H, 4.88; N, 7.74.

\section{4-(2,4-Dichlorophenyl)-5-phenylpyrrolo(spiro[2.3"]oxindole)spiro[3.3']-5'-(2,4-dichlorophenyl}

methylidenedichlorophenylmethylidene)piperidin-4'-one (5g). Obtained as a white solid, (0.144 $\mathrm{g}$, 92\%); mp = 160-161 ${ }^{\circ} \mathrm{C}$; IR (KBr): 1599, 1618, 1704, 3182, $3338 \mathrm{~cm}^{-1}$; ${ }^{1} \mathrm{H}-\mathrm{NMR}\left(300 \mathrm{MHz}, \mathrm{CDCl}_{3}\right)$ : $\delta_{\mathrm{H}} 2.35\left(\mathrm{~d}, 1 \mathrm{H}, J=13.5 \mathrm{~Hz}, 2^{\prime}-\mathrm{CH}_{2}\right), 3.23-3.42\left(\mathrm{~m}, 2 \mathrm{H}, 2^{\prime}-\mathrm{CH}_{2}\right.$ and $\left.6{ }^{\prime}-\mathrm{CH}_{2}\right), 3.56(\mathrm{~d}, 1 \mathrm{H}, J=15.3 \mathrm{~Hz}$, 6'- $\left.\mathrm{CH}_{2}\right), 5.04(\mathrm{~d}, 1 \mathrm{H}, J=9.3 \mathrm{~Hz}, 4-\mathrm{CH}), 5.58(\mathrm{~d}, 1 \mathrm{H}, J=9.3 \mathrm{~Hz}, 5-\mathrm{CH}), 6.69$ (d, 1H, J = 7.2 Hz, Ar-H), $6.88(\mathrm{~d}, 1 \mathrm{H}, J=8.1 \mathrm{~Hz}, \mathrm{Ar}-\mathrm{H}), 6.97(\mathrm{~d}, 1 \mathrm{H}, J=7.5 \mathrm{~Hz}, \mathrm{Ar}-\mathrm{H}), 7.12-7.29$ (m, 5H, Ar-H), 7.40 (s, 1H, Ar-H), 7.54 (d, 2H, $J=7.2 \mathrm{~Hz}, \mathrm{Ar}-\mathrm{H}), 7.61$ (d, 2H, $J=7.8 \mathrm{~Hz}, \mathrm{Ar}-\mathrm{H}), 7.76(\mathrm{~s}, 1 \mathrm{H}, \mathrm{C}=\mathrm{CH}), 7.88(\mathrm{~d}$, $1 \mathrm{H}, J=7.2 \mathrm{~Hz}, \mathrm{Ar}-\mathrm{H}), 8.09$ (d, 1H, $J=8.1 \mathrm{~Hz}, \mathrm{Ar}-\mathrm{H}), 8.90(\mathrm{~s}, 1 \mathrm{H}, 1 "-\mathrm{NH}) .{ }^{13} \mathrm{C}-\mathrm{NMR}(75 \mathrm{MHz}$, $\left.\mathrm{CDCl}_{3}\right): \delta_{\mathrm{C}} 48.49,50.62,54.85,64.54,65.89,75.09,110.16,123.42,127.13,127.47,127.64,128.02$, $128.43,129.12,129.42,129.52,130.18,131.16,131.93,132.21,133.64,134.12,134.92,135.27$, 135.51, 135.71, 136.34, 137.08, 140.77, 141.75, 179.13, 200.24. Anal. calcd for $\mathrm{C}_{34} \mathrm{H}_{25} \mathrm{Cl}_{4} \mathrm{~N}_{3} \mathrm{O}_{2}$ : C, 62.88; H, 3.88; N, 6.47; found: C, 62.75; H, 3.97; N, 6.40.

\section{4-(3-Nitrophenyl)-5-phenylpyrrolo(spiro[2.3"]oxindole)spiro[3.3']-5'-(3-nirophenylmethylidene)}

piperidin-4'-one (5h). Obtained as a white solid, (0.149 g, 91\%); $\mathrm{mp}=154-155^{\circ} \mathrm{C}$; IR (KBr): 1596, 1612, 1702, 3186, $3336 \mathrm{~cm}^{-1} ;{ }^{1} \mathrm{H}-\mathrm{NMR}\left(300 \mathrm{MHz}, \mathrm{CDCl}_{3}\right): \delta_{\mathrm{H}} 2.26\left(\mathrm{~d}, 1 \mathrm{H}, J=12.9 \mathrm{~Hz}, 2^{\prime}-\mathrm{CH}_{2}\right)$, 3.43-3.85 (m, 3H, 2'- $\mathrm{CH}_{2}$ and 6'- $\left.\mathrm{CH}_{2}\right), 4.78$ (d, 1H, $\left.J=10.5 \mathrm{~Hz}, 4-\mathrm{CH}\right), 5.43$ (d, 1H, $\left.J=10.5 \mathrm{~Hz}, 5-\mathrm{CH}\right)$, $6.70(\mathrm{~m}, 11 \mathrm{H}, \mathrm{Ar}-\mathrm{H}), 7.80(\mathrm{~s}, 1 \mathrm{H}, \mathrm{C}=\mathrm{CH}), 7.87-8.13(\mathrm{~m}, 4 \mathrm{H}, \mathrm{Ar}-\mathrm{H}), 8.20(\mathrm{~s}, 1 \mathrm{H}, \mathrm{Ar}-\mathrm{H}), 8.35(\mathrm{~s}, 1 \mathrm{H}$, $\mathrm{Ar}-\mathrm{H}), 8.76$ (s, 1H, $1 "-\mathrm{NH}) .{ }^{13} \mathrm{C}-\mathrm{NMR}\left(75 \mathrm{MHz}, \mathrm{CDCl}_{3}\right): \delta_{\mathrm{C}} 48.33,56.82,63.88,65.01,67.37,72.16$, $110.16,122.62,123.71,124.55,125.02,127.31,127.95,128.50,129.01,129.42,129.71,129.84$, $130.17,134.77,135.81,136.76,136.88,137.20,140.01,140.29,141.81,148.46,148.64,181.44$, 199.69. Anal. calcd for $\mathrm{C}_{34} \mathrm{H}_{27} \mathrm{~N}_{5} \mathrm{O}_{6}$ : C, 67.88; H, 4.52; N, 11.64; found: C, 67.73; H, 4.73; N, 11.46 .

4-(4-Methylphenyl)-5-phenylpyrrolo(spiro[2.3"]oxindole)spiro[3.3']-5'-(4-methylphenylmethylidene) piperidin-4'-one (5i). Obtained as a pale yellow solid, (0.164 g, 92\%); mp = 157-158 ${ }^{\circ} \mathrm{C}$; IR (KBr): 1597, 1615, 1690, 3181, $3340 \mathrm{~cm}^{-1}$; ${ }^{1} \mathrm{H}-\mathrm{NMR}\left(300 \mathrm{MHz}, \mathrm{CDCl}_{3}\right): \delta_{\mathrm{H}} 2.25\left(\mathrm{~s}, 1 \mathrm{H}, \mathrm{CH}_{3}\right), 2.29(\mathrm{~s}, 1 \mathrm{H}$, 
$\left.\mathrm{CH}_{3}\right), 2.34\left(\mathrm{~d}, 1 \mathrm{H}, J=13.2 \mathrm{~Hz}, 2^{\prime}-\mathrm{CH}_{2}\right), 3.50\left(\mathrm{~d}, 1 \mathrm{H}, J=15.0 \mathrm{~Hz}, 6^{\prime}-\mathrm{CH}_{2}\right), 3.60(\mathrm{~d}, 1 \mathrm{H}, J=15.0 \mathrm{~Hz}$, 6'- $\left.\mathrm{CH}_{2}\right), 3.70\left(\mathrm{~d}, 1 \mathrm{H}, J=13.2 \mathrm{~Hz}, 2^{\prime}-\mathrm{CH}_{2}\right), 4.68(\mathrm{~d}, 1 \mathrm{H}, J=10.5 \mathrm{~Hz}, 4-\mathrm{CH}), 5.40(\mathrm{~d}, 1 \mathrm{H}, J=10.5 \mathrm{~Hz}$, 5-CH), 6.65 (d, 1H, $J=7.5 \mathrm{~Hz}, \mathrm{Ar}-\mathrm{H}), 6.76(\mathrm{~d}, 1 \mathrm{H}, J=7.8 \mathrm{~Hz}, \mathrm{Ar}-\mathrm{H}), 6.91$ (d, 2H, $J=8.1 \mathrm{~Hz}, \mathrm{Ar}-\mathrm{H})$, 6.97-7.30 (m, 12H, Ar-H), 7.52 (d, 2H, $J=6.9 \mathrm{~Hz}, \mathrm{Ar}-\mathrm{H}), 8.72(\mathrm{~s}, 1 \mathrm{H}, 1 "-\mathrm{NH}) .{ }^{13} \mathrm{C}-\mathrm{NMR}(75 \mathrm{MHz}$, $\left.\mathrm{CDCl}_{3}\right): \delta_{\mathrm{C}} 21.49,21.77,48.63,50.03,57.33,64.90,67.44,72.62,109.86,122.53,127.31,127.95$, $128.11,128.76,129.24,129.42,129.46,130.17,130.58,132.73,134.46,134.73,135.52,136.76$, 137.66, 139.52, 141.30, 141.69, 181.55, 200.83. Anal. calcd for $\mathrm{C}_{36} \mathrm{H}_{33} \mathrm{~N}_{3} \mathrm{O}_{2}: \mathrm{C}, 80.12 ; \mathrm{H}, 6.16 ; \mathrm{N}$, 7.79; found: C, 80.03; H, 6.24; N, 7.85.

4-(4-Methoxyphenyl)-5-phenylpyrrolo(spiro[2.3"] oxindole)spiro[3.3']-5'-(4-methoxyphenylmethyl idene)piperidin-4'-one (5j). Obtained as a pale yellow solid, $(0.146 \mathrm{~g}, 86 \%)$; $\mathrm{mp}=159-160{ }^{\circ} \mathrm{C}$; IR (KBr): 1598, 1620, 1710, 3179, $3347 \mathrm{~cm}^{-1}$; ${ }^{1} \mathrm{H}-\mathrm{NMR}\left(300 \mathrm{MHz}, \mathrm{CDCl}_{3}\right): \delta_{\mathrm{H}} 2.44(\mathrm{~d}, 1 \mathrm{H}, J=13.8 \mathrm{~Hz}$, $\left.2^{\prime}-\mathrm{CH}_{2}\right), 3.28-3.63\left(\mathrm{~m}, 3 \mathrm{H}, 6^{\prime}-\mathrm{CH}_{2}\right.$ and 2'- $\left.-\mathrm{CH}_{2}\right), 3.66\left(\mathrm{~s}, 3 \mathrm{H}, \mathrm{CH}_{3}\right), 3.85\left(\mathrm{~s}, 3 \mathrm{H}, \mathrm{OCH}_{3}\right), 4.89(\mathrm{~d}, 1 \mathrm{H}$, $J=9.9 \mathrm{~Hz}, 4-\mathrm{CH}), 5.74$ (d, 1H, $J=9.9 \mathrm{~Hz}, 5-\mathrm{CH}), 6.69-7.87$ (m, 18H, Ar-H), 8.20 (s, 1H, 1"-NH). ${ }^{13} \mathrm{C}-\mathrm{NMR}\left(75 \mathrm{MHz}, \mathrm{CDCl}_{3}\right): \delta_{\mathrm{C}} 48.53,50.07,55.42,55.79,57.46,64.93,67.51,72.69,110.35,111.05$, $111.11,120.30,120.50,121.09,122.86,124.74,127.38,127.87,128.07,128.31,128.84,129.41$, 130.52, 130.85, 131.03, 141.81, 158.52, 158.76, 181.22, 199.93. Anal. calcd for $\mathrm{C}_{36} \mathrm{H}_{33} \mathrm{~N}_{3} \mathrm{O}_{4}: \mathrm{C}, 75.64$; H, 5.82; N, 7.35; found: C, 75.78; H, 5.93; N, 7.42.

4-(4-Chlorophenyl)-5-phenylpyrrolo(spiro[2.3"]oxindole)spiro[3.3']-5'-(4-chlorophenylmethylidene) piperidin-4'-one (5k). Obtained as a pale yellow solid, $(0.151 \mathrm{~g}, 90 \%) ; \mathrm{mp}=154-155{ }^{\circ} \mathrm{C}$; $\mathrm{IR}(\mathrm{KBr})$ : 1598, 1618, 1711, 3179, $3338 \mathrm{~cm}^{-1}$; ${ }^{1} \mathrm{H}-\mathrm{NMR}\left(300 \mathrm{MHz}, \mathrm{CDCl}_{3}\right): \delta_{\mathrm{H}} 2.09(\mathrm{~s}, 1 \mathrm{H}, \mathrm{NH}), 2.27(\mathrm{~d}, 1 \mathrm{H}$, $\left.J=13.2 \mathrm{~Hz}, 2^{\prime}-\mathrm{CH}_{2}\right), 3.46-3.60\left(\mathrm{~m}, 2 \mathrm{H}, 6{ }^{\prime}-\mathrm{CH}_{2}\right), 3.72\left(\mathrm{~d}, 1 \mathrm{H}, J=13.2 \mathrm{~Hz}, 2^{\prime}-\mathrm{CH}_{2}\right), 4.67(\mathrm{~d}, 1 \mathrm{H}$, $J=10.8 \mathrm{~Hz}, 4-\mathrm{CH}), 5.35(\mathrm{~d}, 1 \mathrm{H}, J=10.8 \mathrm{~Hz}, 5-\mathrm{CH}), 6.67(\mathrm{~d}, 1 \mathrm{H}, J=7.2 \mathrm{~Hz}, \mathrm{Ar}-\mathrm{H}), 6.77(\mathrm{~d}, 1 \mathrm{H}$, $J=7.2 \mathrm{~Hz}, \mathrm{Ar}-\mathrm{H}), 6.90-7.54(\mathrm{~m}, 16 \mathrm{H}, \mathrm{Ar}-\mathrm{H}), 8.49(\mathrm{~s}, 1 \mathrm{H}, 1 "-\mathrm{NH}) .{ }^{13} \mathrm{C}-\mathrm{NMR}\left(75 \mathrm{MHz}, \mathrm{CDCl}_{3}\right): \delta_{\mathrm{C}}$ $48.52,50.03,56.65,64.81,67.43,72.25,109.85,122.58,124.35,127.32,127.98,128.34,128.76$, $128.87,129.00,129.31,129.53,131.57,132.07,133.16,133.79,135.25,135.42,136.33,140.72$, 141.61, 181.42, 200.18. Anal. calcd for $\mathrm{C}_{34} \mathrm{H}_{27} \mathrm{Cl}_{2} \mathrm{~N}_{3} \mathrm{O}_{2}: \mathrm{C}, 70.35 ; \mathrm{H}, 4.69 ; \mathrm{N}, 7.24$; found: C, 70.51; $\mathrm{H}$, $4.80 ; \mathrm{N}, 7.31$.

4-(4-Bromophenyl)-5-phenylpyrrolo(spiro[2.3"] oxindole)spiro[3.3']-5'-(4-bromophenylmethylidene) piperidin-4'-one (5l). Obtained as a white solid, (0.142 g, 92\%); $\mathrm{mp}=166-167{ }^{\circ} \mathrm{C}$; IR (KBr): 1597 , 1615, 1705, 3174, $3340 \mathrm{~cm}^{-1}$; ${ }^{1} \mathrm{H}-\mathrm{NMR}\left(300 \mathrm{MHz}, \mathrm{CDCl}_{3}\right): \delta_{\mathrm{H}} 2.08(\mathrm{~s}, 1 \mathrm{H}, \mathrm{NH}), 2.27(\mathrm{~d}, 1 \mathrm{H}, J=12.9 \mathrm{~Hz}$, 2'- $\left.\mathrm{CH}_{2}\right), 3.46-3.79\left(\mathrm{~m}, 3 \mathrm{H}, 6^{\prime}-\mathrm{CH}_{2}\right.$ and 2'- $\left.\mathrm{CH}_{2}\right), 4.66(\mathrm{~d}, 1 \mathrm{H}, J=10.8 \mathrm{~Hz}, 4-\mathrm{CH}), 5.34(\mathrm{~d}, 1 \mathrm{H}, J=10.8 \mathrm{~Hz}$, 5-CH), 6.66-6.72 (m, 2H, Ar-H), 6.84 (d, 2H, J=8.1 Hz, Ar-H), 6.93 (s, 1H, C=CH), 6.97-7.51 (m, $13 \mathrm{H}, \mathrm{Ar}-\mathrm{H}), 8.39$ (s, 1H, 1"-NH). ${ }^{13} \mathrm{C}-\mathrm{NMR}\left(75 \mathrm{MHz}, \mathrm{CDCl}_{3}\right): \delta_{\mathrm{C}} 48.52,50.03,56.67,64.73,67.43$, $72.21,109.84,121.36,122.59,123.59,127.98,128.24,128.88,129.54,129.77,130.18,131.77$, $131.85,131.97,132.27,134.23,135.53,136.37,136.79,140.69,141.58,181.33,200.14$. Anal. calcd for $\mathrm{C}_{34} \mathrm{H}_{27} \mathrm{Br}_{2} \mathrm{~N}_{3} \mathrm{O}_{2}$ : C, 61.00; H, 4.07; N, 6.28; found: C, 61.17; H, 4.21; N, 6.35.

4-(4-Fluorophenyl)-5-phenylpyrrolo(spiro[2.3"]oxindole)spiro[3.3']-5'-(4-fluorophenylmethylidene) piperidin-4'-one $(\mathbf{5 m})$. Obtained as a pale yellow solid, $(0.164 \mathrm{~g}, 93 \%) ; \mathrm{mp}=159-160{ }^{\circ} \mathrm{C}$; IR $(\mathrm{KBr})$ : 1596, 1617, 1700, 3181, $3346 \mathrm{~cm}^{-1}$; ${ }^{1} \mathrm{H}-\mathrm{NMR}\left(300 \mathrm{MHz}, \mathrm{CDCl}_{3}\right): \delta_{\mathrm{H}} 2.13(\mathrm{~s}, 1 \mathrm{H}, \mathrm{NH}), 2.28(\mathrm{~d}, 1 \mathrm{H}$, 
$\left.J=13.2 \mathrm{~Hz}, 2^{\prime}-\mathrm{CH}_{2}\right), 3.48\left(\mathrm{~d}, 1 \mathrm{H}, J=14.7 \mathrm{~Hz}, 6{ }^{\prime}-\mathrm{CH}_{2}\right), 3.58\left(\mathrm{~d}, 1 \mathrm{H}, J=14.7 \mathrm{~Hz}, 6{ }^{\prime}-\mathrm{CH}_{2}\right), 3.70(\mathrm{~d}$, $\left.1 \mathrm{H}, J=13.2 \mathrm{~Hz}, 2^{\prime}-\mathrm{CH}_{2}\right), 4.67(\mathrm{~d}, 1 \mathrm{H}, J=10.5 \mathrm{~Hz}, 4-\mathrm{CH}), 5.34(\mathrm{~d}, 1 \mathrm{H}, J=10.5 \mathrm{~Hz}, 5-\mathrm{CH}), 6.68(\mathrm{~d}$, $2 \mathrm{H}, J=7.5 \mathrm{~Hz}, \mathrm{Ar}-\mathrm{H}), 6.89-7.55$ (m, 16H, Ar-H), 8.58 (s, 1H, 1"-NH). ${ }^{13} \mathrm{C}-\mathrm{NMR}\left(75 \mathrm{MHz}, \mathrm{CDCl}_{3}\right)$ : $\delta_{\mathrm{C}} 48.50,50.05,56.79,65.10,67.27,72.40,109.86,115.56\left({ }^{2} J_{\mathrm{CF}}=21.0 \mathrm{~Hz}\right), 115.88\left({ }^{2} J_{\mathrm{CF}}=21.5 \mathrm{~Hz}\right)$, $122.56,127.33,127.99,128.15,128.83,129.41,129.46,130.17,131.76,132.30,133.43,134.77$, 136.55, 140.93, 141.65, $162.23\left({ }^{1} J_{\mathrm{CF}}=244.1 \mathrm{~Hz}\right), 163.13\left({ }^{1} J_{\mathrm{CF}}=248.9 \mathrm{~Hz}\right), 181.43,200.42$. Anal. calcd for $\mathrm{C}_{34} \mathrm{H}_{27} \mathrm{~F}_{2} \mathrm{~N}_{3} \mathrm{O}_{2}$ : C, 74.57; H, 4.97; N, 7.67; found: C, 74.69; H, 4.90; N, 7.76.

4-(1-Naphthyl)-5-phenylpyrrolo(spiro[2.3"] oxindole)spiro[3.3']-5'-(1-naphthylmethylidene)piperidin$4^{\prime}$-one (5n). Obtained as a yellow solid, (0.142 g, 87\%); mp = 164-165 ${ }^{\circ} \mathrm{C}$; IR (KBr): 1590, 1619, 1704, 3174, $3335 \mathrm{~cm}^{-1}$; ${ }^{1} \mathrm{H}-\mathrm{NMR}\left(300 \mathrm{MHz}, \mathrm{CDCl}_{3}\right): \delta_{\mathrm{H}} 1.94(\mathrm{~s}, 1 \mathrm{H}, \mathrm{NH}), 2.07$ (d, $1 \mathrm{H}, J=12.9 \mathrm{~Hz}$, $\left.2^{\prime}-\mathrm{CH}_{2}\right), 3.18-3.73\left(\mathrm{~m}, 3 \mathrm{H}, 6{ }^{\prime}-\mathrm{CH}_{2}\right.$ and $\left.2^{\prime}-\mathrm{CH}_{2}\right), 5.58(\mathrm{~d}, 1 \mathrm{H}, J=9.9 \mathrm{~Hz}, 4-\mathrm{CH}), 5.80(\mathrm{~d}, 1 \mathrm{H}, J=9.9 \mathrm{~Hz}$, 5-CH), 6.71-8.06 (m, 24H, Ar-H), $8.50(\mathrm{~s}, 1 \mathrm{H}, 1 "-\mathrm{NH}) .{ }^{13} \mathrm{C}-\mathrm{NMR}\left(75 \mathrm{MHz}, \mathrm{CDCl}_{3}\right): \delta_{\mathrm{C}} 48.70,50.15$, 56.53, 64.71, 67.46, 72.20, 109.83, 122.96, 124.46, 125.04, 125.41, 126.45, 126.73, 127.12, 127.24, $127.58,127.84,127.98,128.61,128.82,129.05,129.20,129.41,129.99,130.16,132.41,132.64$, $133.24,133.84,134.84,135.15,135.62,136.91,137.01,144.40,181.38,200.13$. Anal. calcd for $\mathrm{C}_{42} \mathrm{H}_{33} \mathrm{~N}_{3} \mathrm{O}_{2}$ : C, 82.46; H, 5.44; N, 6.87; found: C, 82.39; H, 5.56; N, 6.80.

Spiro[2.3"]oxindole-spiro[3.3']-5'-(phenylmethylidene)-tetrahydro-4'(1H)-pyridinone-4-(phenyl) hexahydro-1H-pyrrolizine (6a). Obtained as a white solid, $(0.165 \mathrm{~g}, 94 \%) ; \mathrm{mp}=182-188{ }^{\circ} \mathrm{C}$; IR (KBr): 1610, 1618, 1706, $3390 \mathrm{~cm}^{-1}$; ${ }^{1} \mathrm{H}-\mathrm{NMR}\left(400 \mathrm{MHz}, \mathrm{CDCl}_{3}\right): \delta_{\mathrm{H}} 1.60-1.69\left(\mathrm{~m}, 1 \mathrm{H}, 5-\mathrm{CH}_{2}\right)$, $1.82-2.01\left(\mathrm{~m}, 2 \mathrm{H}, 6-\mathrm{CH}_{2}\right), 2.04-2.14\left(\mathrm{~m}, 1 \mathrm{H}, 5-\mathrm{CH}_{2}\right), 2.33\left(\mathrm{~d}, 1 \mathrm{H}, J=13.2 \mathrm{~Hz}, 2^{\prime}-\mathrm{CH}_{2}\right), 2.60(\mathrm{td}, 1 \mathrm{H}$, $\left.J=8.8,2.4 \mathrm{~Hz}, 7-\mathrm{CH}_{2}\right), 3.07-3.13\left(\mathrm{~m}, 1 \mathrm{H}, 7-\mathrm{CH}_{2}\right), 3.39\left(\mathrm{~d}, 1 \mathrm{H}, J=14.8 \mathrm{~Hz}, 6{ }^{\prime}-\mathrm{CH}_{2}\right), 3.62(\mathrm{~d}, 1 \mathrm{H}$, $\left.J=14.8 \mathrm{~Hz}, 6^{\prime}-\mathrm{CH}_{2}\right), 3.96\left(\mathrm{~d}, 1 \mathrm{H}, J=13.2 \mathrm{~Hz}, 2^{\prime}-\mathrm{CH}_{2}\right), 4.38(\mathrm{~d}, 1 \mathrm{H}, J=11.2 \mathrm{~Hz}, 4-\mathrm{CH}), 4.62-4.70$ (m, 1H, 4a-CH), 6.73 (d, 1H, $J=6.8 \mathrm{~Hz}, \mathrm{Ar}-\mathrm{H}), 6.94-7.02(\mathrm{~m}, 3 \mathrm{H}, \mathrm{Ar}-\mathrm{H}), 7.15-7.31$ (m, 9H, Ar-H and arylmethylidene), 7.37 (d, 2H, $J=7.6 \mathrm{~Hz}, \mathrm{Ar}-\mathrm{H}), 8.87$ (s, 1H, 1"-NH). ${ }^{13} \mathrm{C}-\mathrm{NMR}(100 \mathrm{MHz}$, $\left.\mathrm{CDCl}_{3}\right): \delta_{\mathrm{C}} 26.28,29.29,48.13,48.35,49.30,53.64,66.52,71.88,74.81,109.97,121.78,127.23$, $128.62,128.69,128.93,129.36,129.39,130.03,130.14,135.58,136.18,136.30,137.95,142.06,180.06$, 200.63. Anal. calcd for $\mathrm{C}_{31} \mathrm{H}_{29} \mathrm{~N}_{3} \mathrm{O}_{2}$ : C, 78.29; $\mathrm{H}, 6.15 ; \mathrm{N}, 8.84 \%$; found: $\mathrm{C}, 78.12 ; \mathrm{H}, 6.33 ; \mathrm{N}, 8.95 \%$.

Spiro[2.3"] oxindole-spiro[3.3']-5'-(2-methylphenylmethylidene)tetrahydro-4'(1H)-pyridinone-4-(2methylphenyl)hexahydro-1H-pyrrolizine (6b). Obtained as a white solid, $(0.154 \mathrm{~g}, 93 \%) ; \mathrm{mp}=$ 184-185 ${ }^{\circ} \mathrm{C}$; IR (KBr): 1605, 1622, 1705, $3387 \mathrm{~cm}^{-1}$; ${ }^{1} \mathrm{H}-\mathrm{NMR}\left(300 \mathrm{MHz}, \mathrm{CDCl}_{3}\right): \delta_{\mathrm{H}} 1.58-1.70(\mathrm{~m}$, $\left.1 \mathrm{H}, 5-\mathrm{CH}_{2}\right), 1.78-2.04\left(\mathrm{~m}, 3 \mathrm{H}, 6-\mathrm{CH}_{2}\right.$ and 5- $\left.\mathrm{CH}_{2}\right), 2.30\left(\mathrm{~s}, 3 \mathrm{H}, \mathrm{CH}_{3}\right), 2.31\left(\mathrm{~s}, 3 \mathrm{H}, \mathrm{CH}_{3}\right), 2.42(\mathrm{~d}, 1 \mathrm{H}$, $\left.J=12.9 \mathrm{~Hz}, 2^{\prime}-\mathrm{CH}_{2}\right), 2.64\left(\mathrm{td}, 1 \mathrm{H}, J=8.1,3.0 \mathrm{~Hz}, 7-\mathrm{CH}_{2}\right), 3.09-3.17$ (m, 1H, 7-CH $), 3.61(\mathrm{dd}, 1 \mathrm{H}$, $\left.J=15.0,2.1 \mathrm{~Hz}, 6^{\prime}-\mathrm{CH}_{2}\right), 3.97\left(\mathrm{~d}, 1 \mathrm{H}, J=15.0 \mathrm{~Hz}, 6^{\prime}-\mathrm{CH}_{2}\right), 4.19\left(\mathrm{~d}, 1 \mathrm{H}, J=12.9 \mathrm{~Hz}, 2^{\prime}-\mathrm{CH}_{2}\right), 4.62$ (d, $1 \mathrm{H}, J=10.8 \mathrm{~Hz}, 4-\mathrm{CH}), 4.82-4.86(\mathrm{~m}, 1 \mathrm{H}, 4 \mathrm{a}-\mathrm{CH}), 6.62$ (d, 1H, J = 7.5 Hz, Ar-H), 6.87-7.25 (m, 10H, Ar-H), 7.53-7.63 (m, 2H, Ar-H and arylmethylidene), 8.03 (s, 1H, 1"-NH). ${ }^{13} \mathrm{C}-\mathrm{NMR}$ (75 MHz, $\left.\mathrm{CDCl}_{3}\right): \delta_{\mathrm{C}} 20.39,21.12,26.08,28.59,47.19,48.92,49.22,53.22,65.83,70.05,74.73,110.12,122.47$, $125.78,125.95,127.34,128.61,129.30,129.42,129.59,130.62,130.80,131.13,133.45,134.52$, 135.11, 136.61, 138.26, 138.77, 141.61, 180.74, 202.27. Anal. calcd for $\mathrm{C}_{33} \mathrm{H}_{33} \mathrm{~N}_{3} \mathrm{O}_{2}$ : C, 78.70; $\mathrm{H}$, $6.60 ; \mathrm{N}, 8.34 \%$; found: C, 78.59; H, 6.76; N, 8.25\%. 
Spiro[2.3"]oxindole-spiro[3.3']-5'-(2-methoxyphenylmethylidene)tetrahydro-4'(1H)-pyridinone-4-(2methoxyphenyl)hexahydro-1H-pyrrolizine (6c). Obtained as a brown solid, $(0.140 \mathrm{~g}, 88 \%) ; \mathrm{mp}=$ 187-188 ${ }^{\circ} \mathrm{C}$; IR (KBr): 1603, 1619, 1702, $3389 \mathrm{~cm}^{-1}$; ${ }^{1} \mathrm{H}-\mathrm{NMR}\left(300 \mathrm{MHz}, \mathrm{CDCl}_{3}\right): \delta_{\mathrm{H}} 1.69-2.00(\mathrm{~m}$, $4 \mathrm{H}, 5-\mathrm{CH}_{2}$ and $\left.6-\mathrm{CH}_{2}\right), 2.62\left(\mathrm{~d}, 1 \mathrm{H}, J=12.9 \mathrm{~Hz}, 2 \mathrm{C}-\mathrm{CH}_{2}\right), 2.83\left(\mathrm{td}, 1 \mathrm{H}, J=8.1,3.0 \mathrm{~Hz}, 7-\mathrm{CH}_{2}\right)$, 3.30-3.43 (m, 1H, 7-CH $), 3.65\left(\mathrm{~s}, 3 \mathrm{H}, \mathrm{OCH}_{3}\right), 3.71-3.81\left(\mathrm{~m}, 1 \mathrm{H}, 6^{\prime}-\mathrm{CH}_{2}\right), 3.85\left(\mathrm{~s}, 3 \mathrm{H}, \mathrm{OCH}_{3}\right), 3.99-4.15$ (m, 2H, 6'- $\mathrm{CH}_{2}$ and 2'- $\mathrm{CH}_{2}$ ), 4.64 (d, 1H, $\left.J=10.8 \mathrm{~Hz}, 4-\mathrm{CH}\right), 4.82-4.87$ (m, 1H, 4a-CH), 6.62-7.37 (m, 12H, Ar-H and arylmethylidene), $7.51(\mathrm{~d}, 1 \mathrm{H}, J=7.2 \mathrm{~Hz}, \mathrm{Ar}-\mathrm{H}), 8.02(\mathrm{~s}, 1 \mathrm{H}, 1 "-\mathrm{NH}) .{ }^{13} \mathrm{C}-\mathrm{NMR}$ $\left(75 \mathrm{MHz}, \mathrm{CDCl}_{3}\right): \delta_{\mathrm{C}} 25.31,27.97,48.65,49.36,50.51,54.02,54.97,55.88,65.45,70.05,74.18$, $110.51,111.11,111.17,120.49$, 120.90, 122.44, 125.24, 126.17, 128.17, 128.33, 129.61, 130.69, $130.84,131.03,132.16,135.25,135.58,142.01,158.02,158.79,180.27,201.51$. Anal. calcd for $\mathrm{C}_{33} \mathrm{H}_{33} \mathrm{~N}_{3} \mathrm{O}_{4}$ : C, 74.00; H, 6.21; N, 7.84\%; found: C, 74.21; H, 6.10; N, 7.98\%.

Spiro[2.3"]oxindole-spiro[3.3']-5'-(2-chlorophenylmethylidene)tetrahydro-4'(1H)-pyridinone-4-(2chlorophenyl)hexahydro-1H-pyrrolizine (6d). Obtained as a pale yellow solid, (0.145 g, 92\%); $\mathrm{mp}=172-173{ }^{\circ} \mathrm{C}$; IR (KBr): 1605, 1618, 1702, $3389 \mathrm{~cm}^{-1} ;{ }^{1} \mathrm{H}-\mathrm{NMR}\left(300 \mathrm{MHz}, \mathrm{CDCl}_{3}\right): \delta_{\mathrm{H}} 1.79-2.19$ $\left(\mathrm{m}, 4 \mathrm{H}, 5-\mathrm{CH}_{2}\right.$ and $\left.6-\mathrm{CH}_{2}\right), 2.39\left(\mathrm{~d}, 1 \mathrm{H}, J=12.9 \mathrm{~Hz}, 2^{\prime}-\mathrm{CH}_{2}\right), 2.59-2.64\left(\mathrm{~m}, 1 \mathrm{H}, 7-\mathrm{CH}_{2}\right), 3.22-3.28$ $\left(\mathrm{m}, 1 \mathrm{H}, 7-\mathrm{CH}_{2}\right), 3.45-3.66\left(\mathrm{~m}, 2 \mathrm{H}, 6{ }^{\prime}-\mathrm{CH}_{2}\right), 3.95\left(\mathrm{~d}, 1 \mathrm{H}, J=12.9 \mathrm{~Hz}, 2^{\prime}-\mathrm{CH}_{2}\right), 4.55-4.60(\mathrm{~m}, 1 \mathrm{H}$, 4-CH), 4.82-4.87 (m, 1H, 4a-CH), 6.61-7.74 (m, 13H, Ar-H and arylmethylidene), $8.72(\mathrm{~s}, 1 \mathrm{H}$, $1 "-\mathrm{NH}) .{ }^{13} \mathrm{C}-\mathrm{NMR}\left(75 \mathrm{MHz}, \mathrm{CDCl}_{3}\right): \delta_{\mathrm{C}} 25.81,28.35,48.10,48.27,48.81,52.20,64.19,70.19,74.78$, $110.10,122.62,126.78,126.86,127.54,128.74,130.14,130.54,130.85,131.06,132.04,132.92$, $133.34,133.60,133.85,135.47,136.42,136.66,137.46,141.69,180.46,201.23$. Anal. calcd for $\mathrm{C}_{31} \mathrm{H}_{27} \mathrm{Cl}_{2} \mathrm{~N}_{3} \mathrm{O}_{2}$ : C, 68.38; H, 5.00; N, 7.72\%; found: C, 68.23; H, 5.17; N, 7.61\%.

Spiro[2.3"] oxindole-spiro[3.3']-5'-(2-bromophenylmethylidene)tetrahydro-4'(1H)-pyridinone-4-(2bromophenyl)hexahydro-1H-pyrrolizine (6e). Obtained as a light brown solid, (0.134 g, 92\%); $\mathrm{mp}=164-165{ }^{\circ} \mathrm{C}$; IR (KBr): 1604, 1619, 1700, $3391 \mathrm{~cm}^{-1} ;{ }^{1} \mathrm{H}-\mathrm{NMR}\left(300 \mathrm{MHz}, \mathrm{CDCl}_{3}\right): \delta_{\mathrm{H}} 1.67-2.14$ (m, 4H, 5- $\mathrm{CH}_{2}$ and 6- $\left.\mathrm{CH}_{2}\right), 2.24-2.28\left(\mathrm{~m}, 1 \mathrm{H}, 2^{\prime}-\mathrm{CH}_{2}\right), 2.52-2.65\left(\mathrm{~m}, 1 \mathrm{H}, 7-\mathrm{CH}_{2}\right), 3.22-3.29(\mathrm{~m}, 1 \mathrm{H}$, 7-CH $\left.\mathrm{CH}_{2}\right), 3.46-3.61\left(\mathrm{~m}, 2 \mathrm{H}, 6{ }^{\prime}-\mathrm{CH}_{2}\right), 3.92\left(\mathrm{~d}, 1 \mathrm{H}, J=12.9 \mathrm{~Hz}, 2^{\prime}-\mathrm{CH}_{2}\right), 4.55-4.60(\mathrm{~m}, 1 \mathrm{H}, 4-\mathrm{CH}), 4.80-4.90$ (m, 1H, 4a-CH), $6.60(\mathrm{~d}, 1 \mathrm{H}, J=7.2 \mathrm{~Hz}, \mathrm{Ar}-\mathrm{H}), 6.76-7.655(\mathrm{~m}, 11 \mathrm{H}$, Ar-H and arylmethylidene), 7.75 (d, $1 \mathrm{H}, J=7.2 \mathrm{~Hz}, \mathrm{Ar}-\mathrm{H}), 8.99$ (s, $1 \mathrm{H}, 1 "-\mathrm{NH}) .{ }^{13} \mathrm{C}-\mathrm{NMR}\left(75 \mathrm{MHz}, \mathrm{CDCl}_{3}\right): \delta_{\mathrm{C}} 25.75,28.46,47.89$, $48.09,48.61,51.55,64.19,70.91,75.32,110.23,122.47,125.66,127.39,127.50,127.61,129.09$, $130.68,130.87,131.06,133.32,133.54,134.05,134.64,135.58,135.68,135.93,136.27,137.16$, 141.84, 180.50, 201.21. Anal. calcd for $\mathrm{C}_{31} \mathrm{H}_{27} \mathrm{Br}_{2} \mathrm{~N}_{3} \mathrm{O}_{2}$ : C, 58.79; H, 4.30; N, 6.63\%; found: C, 58.93; H, 4.12; N, 6.75\%.

Spiro[2.3"]oxindole-spiro[3.3']-5'-(2-fluorophenylmethylidene)-tetrahydro-4'(1H)-pyridinone-4-(2fluorophenyl)hexahydro-1H-pyrrolizine (6f). Obtained as a white solid; $\mathrm{mp}=198-199{ }^{\circ} \mathrm{C}$; $\mathrm{IR}(\mathrm{KBr})$ : 1606, 1620, 1703, $3392 \mathrm{~cm}^{-1}$; ${ }^{1} \mathrm{H}-\mathrm{NMR}\left(500 \mathrm{MHz}, \mathrm{CDCl}_{3}\right): \delta_{\mathrm{H}} 1.65-1.72\left(\mathrm{~m}, 1 \mathrm{H}, 5-\mathrm{CH}_{2}\right), 1.82-1.88$ (m, $\left.1 \mathrm{H}, 6-\mathrm{CH}_{2}\right), 1.99-2.13\left(\mathrm{~m}, 2 \mathrm{H}, 6-\mathrm{CH}_{2}\right.$ and 5- $\left.\mathrm{CH}_{2}\right), 2.35\left(\mathrm{~d}, 1 \mathrm{H}, J=13.0 \mathrm{~Hz}, 2^{\prime}-\mathrm{CH}_{2}\right), 2.62(\mathrm{td}, 1 \mathrm{H}$, $\left.J=8.0,2.0 \mathrm{~Hz}, 7-\mathrm{CH}_{2}\right), 3.31-3.36\left(\mathrm{~m}, 1 \mathrm{H}, 7-\mathrm{CH}_{2}\right), 3.42-3.50\left(\mathrm{~m}, 2 \mathrm{H}, 6-\mathrm{CH}_{2}\right), 3.87$ (d, $1 \mathrm{H}, J=13.0 \mathrm{~Hz}$, $\left.2^{\prime}-\mathrm{CH}_{2}\right), 4.64(\mathrm{~d}, 1 \mathrm{H}, J=10.5 \mathrm{~Hz}, 4-\mathrm{CH}), 4.81-4.85(\mathrm{~m}, 1 \mathrm{H}, 4 \mathrm{a}-\mathrm{CH}), 6.72(\mathrm{~d}, 1 \mathrm{H}, J=7.5 \mathrm{~Hz}, \mathrm{Ar}-\mathrm{H})$, 6.88 (t, 1H, $J=7.0 \mathrm{~Hz}, \mathrm{Ar}-\mathrm{H}), 6.96-7.04$ (m, 4H, Ar-H), 7.12 (d, 1H, J = 8.0 Hz, Ar-H), 7.15 (d, 1H, 
$J=8.0 \mathrm{~Hz}$, Ar-H), 7.18 (s, 1H, arylmethylidene), 7.20-7.25 (m, 3H, Ar-H), 7.29 (d, 1H, $J=8.0 \mathrm{~Hz}$, $\mathrm{Ar}-\mathrm{H}), 7.59$ (t, $1 \mathrm{H}, J=7.0 \mathrm{~Hz}, \mathrm{Ar}-\mathrm{H}), 8.74$ (s, 1H, 1"-NH). ${ }^{13} \mathrm{C}-\mathrm{NMR}\left(125 \mathrm{MHz}, \mathrm{CDCl}_{3}\right): \delta_{\mathrm{C}} 25.16$, $28.59,47.30,47.87,48.32,49.88,65.78,69.35,74.86,109.50,115.45\left({ }^{2} J_{\mathrm{CF}}=18.0 \mathrm{~Hz}\right), 115.59$ $\left({ }^{2} J_{\mathrm{CF}}=17.0 \mathrm{~Hz}\right), 121.73,123.10\left(J_{\mathrm{CF}}=10.0 \mathrm{~Hz}\right), 123.58\left(J_{\mathrm{CF}}=3.0 \mathrm{~Hz}\right), 123.96\left(J_{\mathrm{CF}}=3.0 \mathrm{~Hz}\right), 124.87$ $\left(J_{\mathrm{CF}}=12.0 \mathrm{~Hz}\right), 126.08,128.36\left(123.10\left(J_{\mathrm{CF}}=7.0 \mathrm{~Hz}\right), 128.95,129.22,129.65\left(J_{\mathrm{CF}}=3.0 \mathrm{~Hz}\right), 130.36\right.$ $\left(J_{\mathrm{CF}}=2.0 \mathrm{~Hz}\right), 130.48\left(J_{\mathrm{CF}}=8.0 \mathrm{~Hz}\right), 130.76\left(J_{\mathrm{CF}}=4.0 \mathrm{~Hz}\right), 136.29,141.62,160.60\left({ }^{1} J_{\mathrm{CF}}=200.0 \mathrm{~Hz}\right)$, 161.86 $\left({ }^{1} J_{\mathrm{CF}}=196.0 \mathrm{~Hz}\right), 179.57,199.06$. Anal. calcd for $\mathrm{C}_{31} \mathrm{H}_{27} \mathrm{~F}_{2} \mathrm{~N}_{3} \mathrm{O}_{2}: \mathrm{C}, 72.78 ; \mathrm{H}, 5.32 ; \mathrm{N}, 8.21 \%$; found: C, 72.96; H, 5.51; N, 8.09\%.

Spiro[2.3"]oxindole-spiro[3.3']-5'-(2,4-chlorophenylmethylidene)tetrahydro-4'(1H)-pyridinone-4-(2,4chlorophenyl)hexahydro-1H-pyrrolizine (6g). Obtained as a pale yellow solid, (0.141 g, 95\%); $\mathrm{mp}=210-21{ }^{\circ} \mathrm{C}$; IR (KBr): 1604, 1620, 1702, $3391 \mathrm{~cm}^{-1} ;{ }^{1} \mathrm{H}-\mathrm{NMR}\left(300 \mathrm{MHz}, \mathrm{CDCl}_{3}\right): \delta_{\mathrm{H}} 1.73-2.29$ $\left(\mathrm{m}, 4 \mathrm{H}, 5-\mathrm{CH}_{2}\right.$ and 6- $\left.\mathrm{CH}_{2}\right), 2.60\left(\mathrm{~d}, 1 \mathrm{H}, J=12.3 \mathrm{~Hz}, 2^{\prime}-\mathrm{CH}_{2}\right), 2.64-2.79\left(\mathrm{~m}, 1 \mathrm{H}, 7-\mathrm{CH}_{2}\right), 3.21-3.30$ (m, 1H, 7- $\left.\mathrm{CH}_{2}\right), 3.52-3.68\left(\mathrm{~m}, 1 \mathrm{H}, 6^{\prime}-\mathrm{CH}_{2}\right), 3.97$ (d, $\left.1 \mathrm{H}, J=15.6 \mathrm{~Hz}, 6{ }^{\prime}-\mathrm{CH}_{2}\right), 4.14(\mathrm{~d}, 1 \mathrm{H}, J=12.3 \mathrm{~Hz}$, $\left.2^{\prime}-\mathrm{CH}_{2}\right), 4.54-4.60(\mathrm{~m}, 1 \mathrm{H}, 4-\mathrm{CH}), 4.83-4.89(\mathrm{~m}, 1 \mathrm{H}, 4 \mathrm{a}-\mathrm{CH}), 6.62-7.92(\mathrm{~m}, 11 \mathrm{H}, \mathrm{Ar}-\mathrm{H}$ and arylmethylidene), $8.75(\mathrm{~s}, 1 \mathrm{H}, 1 "-\mathrm{NH}) .{ }^{13} \mathrm{C}-\mathrm{NMR}\left(75 \mathrm{MHz}, \mathrm{CDCl}_{3}\right): \delta_{\mathrm{C}} 25.82,28.51,48.14,48.54$, $49.25,52.23,65.17,70.21,74.73,110.29,122.77,127.23,127.31,128.37,130.10,130.30,130.73$, 130.87, 131.48, 131.68, 132.26, 132.59, 133.93, 135.49, 135.90, 136.34, 137.15, 141.75, 180.37, 201.14. Anal. calcd for $\mathrm{C}_{31} \mathrm{H}_{25} \mathrm{Cl}_{4} \mathrm{~N}_{3} \mathrm{O}_{2}$ : C, 60.70; $\mathrm{H}, 4.11 ; \mathrm{N}, 6.85 \%$; found: $\mathrm{C}, 60.87 ; \mathrm{H}, 4.23 ; \mathrm{N}, 6.64 \%$.

Spiro[2.3"] oxindole-spiro[3.3']-5'-(3-nitrophenylmethylidene)tetrahydro-4'(1H)-pyridinone-4-(3nitrophenyl)hexahydro-1H-pyrrolizine (6h). Obtained as a pale yellow solid, (0.144 g, 93\%); $\mathrm{mp}=204-205{ }^{\circ} \mathrm{C}$; IR (KBr): 1608, 1621, 1707, $3386 \mathrm{~cm}^{-1} ;{ }^{1} \mathrm{H}-\mathrm{NMR}\left(300 \mathrm{MHz}, \mathrm{CDCl}_{3}\right): \delta_{\mathrm{H}} 1.58-2.02$ $\left(\mathrm{m}, 4 \mathrm{H}, 5-\mathrm{CH}_{2}\right.$ and $\left.6-\mathrm{CH}_{2}\right), 2.27\left(\mathrm{~d}, 1 \mathrm{H}, J=12.6 \mathrm{~Hz}, 2^{\prime}-\mathrm{CH}_{2}\right), 2.60-2.63\left(\mathrm{~m}, 1 \mathrm{H}, 7-\mathrm{CH}_{2}\right), 3.06-3.15$ (m, 1H, 7- $\left.\mathrm{CH}_{2}\right), 3.46-3.51\left(\mathrm{~m}, 1 \mathrm{H}, 6^{\prime}-\mathrm{CH}_{2}\right), 3.62\left(\mathrm{~d}, 1 \mathrm{H}, J=14.7 \mathrm{~Hz}, 6{ }^{\prime}-\mathrm{CH}_{2}\right), 4.01(\mathrm{~d}, 1 \mathrm{H}, J=12.6 \mathrm{~Hz}$, $\left.2^{\prime}-\mathrm{CH}_{2}\right), 4.48(\mathrm{~d}, 1 \mathrm{H}, J=10.8 \mathrm{~Hz}, 4-\mathrm{CH}), 4.65-4.73(\mathrm{~m}, 1 \mathrm{H}, 4 \mathrm{a}-\mathrm{CH}), 6.70-8.25(\mathrm{~m}, 13 \mathrm{H}, \mathrm{Ar}-\mathrm{H}$ and arylmethylidene), $9.10(\mathrm{~s}, 1 \mathrm{H}, 1 "-\mathrm{NH}) .{ }^{13} \mathrm{C}-\mathrm{NMR}\left(75 \mathrm{MHz}, \mathrm{CDCl}_{3}\right): \delta_{\mathrm{C}} 26.10,29.10,48.13,48.86$, 49.07, 51.06, 63.20, 71.89, 74.04, 110.72, 122.78, 123.02, 123.99, 124.68, 125.03, 125.41, 125.90, $127.47,129.68,130.04,133.91,135.68,136.30,136.93,137.33,137.90,141.92,148.45,148.61$, 180.54, 201.06. Anal. calcd for $\mathrm{C}_{31} \mathrm{H}_{27} \mathrm{~N}_{5} \mathrm{O}_{6}$ : C, 65.83; H, 4.81; N, 12.38\%; found: C, 65.69; H, 4.94; $\mathrm{N}, 12.47 \%$.

Spiro[2.3"] oxindole-spiro[3.3']-5'-(4-methylphenylmethylidene)tetrahydro-4'(1H)-pyridinone-4-(4methylphenyl)hexahydro-1H-pyrrolizine (6i). Obtained as a brown solid, $(0.156 \mathrm{~g}, 94 \%) ; \mathrm{mp}=$ 168-169 ${ }^{\circ} \mathrm{C}$; IR (KBr): 1611, 1623, 1704, $3392 \mathrm{~cm}^{-1}$; ${ }^{1} \mathrm{H}-\mathrm{NMR}\left(300 \mathrm{MHz}, \mathrm{CDCl}_{3}\right): \delta_{\mathrm{H}} 1.60-2.03(\mathrm{~m}$, $4 \mathrm{H}, 5-\mathrm{CH}_{2}$ and 6- $\left.\mathrm{CH}_{2}\right), 2.29\left(\mathrm{~d}, 1 \mathrm{H}, J=12.9 \mathrm{~Hz}, 2^{\prime}-\mathrm{CH}_{2}\right), 2.36\left(\mathrm{~s}, 3 \mathrm{H}, \mathrm{CH}_{3}\right), 2.38\left(\mathrm{~s}, 3 \mathrm{H}, \mathrm{CH}_{3}\right), 2.58-2.63$ (m, 1H, 7- $\left.\mathrm{CH}_{2}\right), 3.10-3.16\left(\mathrm{~m}, 1 \mathrm{H}, 7-\mathrm{CH}_{2}\right), 3.49$ (d, $\left.1 \mathrm{H}, J=15.3 \mathrm{~Hz}, 6{ }^{\prime}-\mathrm{CH}_{2}\right), 3.78(\mathrm{~d}, 1 \mathrm{H}, J=15.3 \mathrm{~Hz}$, 6'- $\left.\mathrm{CH}_{2}\right), 3.99-4.03\left(\mathrm{~m}, 1 \mathrm{H}, 2^{\prime}-\mathrm{CH}_{2}\right), 4.36(\mathrm{~d}, 1 \mathrm{H}, J=11.7 \mathrm{~Hz}, 4-\mathrm{CH}), 4.50-4.55(\mathrm{~m}, 1 \mathrm{H}, 4 \mathrm{a}-\mathrm{CH}), 6.66$ (d, $1 \mathrm{H}, J=7.5 \mathrm{~Hz}, \mathrm{Ar}-\mathrm{H}), 6.84-7.54$ (m, 12H, Ar-H and arylmethylidene), 8.56 (s, 1H, 1"-NH). ${ }^{13} \mathrm{C}-\mathrm{NMR}$ $\left(75 \mathrm{MHz}, \mathrm{CDCl}_{3}\right): \delta_{\mathrm{C}} 21.3,21.8,26.07,28.83,48.50,48.78,49.35,53.42,65.96,71.84,74.06,110.25$, $122.61,126.02,129.33,129.66,129.74,130.51,131.01,131.04,132.11,132.78,135.12,136.49$, 
136.97, 139.82, 141.96, 181.00, 202.06. Anal. calcd for $\mathrm{C}_{33} \mathrm{H}_{33} \mathrm{~N}_{3} \mathrm{O}_{2}$ : C, 78.70; $\mathrm{H}, 6.60 ; \mathrm{N}, 8.34 \%$; found: $\mathrm{C}, 78.84 ; \mathrm{H}, 6.42 ; \mathrm{N}, 8.42 \%$.

Spiro[2.3"]oxindole-spiro[3.3']-5'-(4-methoxyphenylmethylidene)tetrahydro-4'(1H)-pyridinone-4-(4methoxyphenyl)hexahydro-1H-pyrrolizine (6j). Obtained as a brown solid, $(0.135 \mathrm{~g}, 85 \%) ; \mathrm{mp}=$ 204-205 ${ }^{\circ} \mathrm{C}$; IR (KBr): 1610, 1623, 1703, $3394 \mathrm{~cm}^{-1}$; ${ }^{1} \mathrm{H}-\mathrm{NMR}\left(300 \mathrm{MHz}, \mathrm{CDCl}_{3}\right): \delta_{\mathrm{H}} 1.58-2.05$ (m, $4 \mathrm{H}, 5-\mathrm{CH}_{2}$ and $\left.6-\mathrm{CH}_{2}\right), 2.32\left(\mathrm{~d}, 1 \mathrm{H}, J=12.6 \mathrm{~Hz}, 2^{\prime}-\mathrm{CH}_{2}\right), 2.57-2.65\left(\mathrm{~m}, 1 \mathrm{H}, 7-\mathrm{CH}_{2}\right), 3.08-3.15(\mathrm{~m}$, $\left.1 \mathrm{H}, 7-\mathrm{CH}_{2}\right), 3.48\left(\mathrm{~d}, 1 \mathrm{H}, J=15.3 \mathrm{~Hz}, 6^{\prime}-\mathrm{CH}_{2}\right), 3.62\left(\mathrm{~s}, 3 \mathrm{H}, \mathrm{OCH}_{3}\right), 3.69\left(\mathrm{~s}, 3 \mathrm{H}, \mathrm{OCH}_{3}\right), 3.82(\mathrm{~d}, 1 \mathrm{H}$, $\left.J=15.3 \mathrm{~Hz}, 6^{\prime}-\mathrm{CH}_{2}\right), 3.97-4.06\left(\mathrm{~m}, 1 \mathrm{H}, 2^{\prime}-\mathrm{CH}_{2}\right), 4.38(\mathrm{~d}, 1 \mathrm{H}, J=11.4 \mathrm{~Hz}, 4-\mathrm{CH}), 4.52-4.56(\mathrm{~m}, 1 \mathrm{H}$, 4a-CH), 6.65-7.54 (m, 13H, Ar-H and arylmethylidene), 8.52 (s, 1H, 1"-NH). ${ }^{13} \mathrm{C}-\mathrm{NMR}(75 \mathrm{MHz}$, $\left.\mathrm{CDCl}_{3}\right): \delta_{\mathrm{C}} 26.12,28.86,47.50,48.18,49.63,53.13,55.20,55.31,64.41,70.34,74.39,110.12,113.45$, 113.92, 122.64, 127.42, 127.86, 129.51, 130.57, 132.21, 132.98, 137.44, 141.53, 158.33, 159.85, 181.03, 201.06. Anal. calcd for $\mathrm{C}_{33} \mathrm{H}_{33} \mathrm{~N}_{3} \mathrm{O}_{4}$ : C, 74.00; H, 6.21; N, 7.84\%; found: C, 74.26; H, 6.14; N, 7.76\%.

Spiro[2.3"] oxindole-spiro[3.3']-5'-(4-chlorophenylmethylidene)tetrahydro-4'(1H)-pyridinone-4-(4chlorophenyl)hexahydro-1H-pyrrolizine (6k). Obtained as a pale yellow solid, (0.150 g, 95\%); $\mathrm{mp}=175-176{ }^{\circ} \mathrm{C}$; IR (KBr): 1610, 1621, 1703, $3387 \mathrm{~cm}^{-1} ;{ }^{1} \mathrm{H}-\mathrm{NMR}\left(300 \mathrm{MHz}, \mathrm{CDCl}_{3}\right): \delta_{\mathrm{H}} 1.56-2.04$ (m, 4H, 5- $\mathrm{CH}_{2}$ and 6- $\left.\mathrm{CH}_{2}\right), 2.29\left(\mathrm{~d}, 1 \mathrm{H}, J=12.9 \mathrm{~Hz}, 2^{\prime}-\mathrm{CH}_{2}\right), 2.58-2.62\left(\mathrm{~m}, 1 \mathrm{H}, 7-\mathrm{CH}_{2}\right), 3.07-3.15$ (m, $\left.1 \mathrm{H}, 7-\mathrm{CH}_{2}\right), 3.49$ (d, $\left.1 \mathrm{H}, J=15.6 \mathrm{~Hz}, 6{ }^{\prime}-\mathrm{CH}_{2}\right), 3.76$ (dd, $\left.1 \mathrm{H}, J=15.6,2.1 \mathrm{~Hz}, 6{ }^{\prime}-\mathrm{CH}_{2}\right), 4.05-4.16$ (m, 1H, 2'- $\left.\mathrm{CH}_{2}\right), 4.35$ (d, 1H, $\left.J=11.4 \mathrm{~Hz}, 4-\mathrm{CH}\right), 4.51-4.56(\mathrm{~m}, 1 \mathrm{H}, 4 \mathrm{a}-\mathrm{CH}), 6.68(\mathrm{~d}, 1 \mathrm{H}, J=7.8 \mathrm{~Hz}$, Ar-H), 6.88-7.55 (m, 12H, Ar-H and arylmethylidene), 8.66 (s, 1H, 1"-NH). ${ }^{13} \mathrm{C}-\mathrm{NMR}(75 \mathrm{MHz}$, $\left.\mathrm{CDCl}_{3}\right): \delta_{\mathrm{C}} 26.08,28.96,48.29,48.85,49.20,53.41,63.99,71.86,74.04,110.43,122.84,125.96$, $128.03,128.82,129.21,129.29,131.73,132.07,132.11,133.63,133.88,135.37,135.49,136.05$, 141.85, 180.74, 201.55. Anal. calcd for $\mathrm{C}_{31} \mathrm{H}_{27} \mathrm{Cl}_{2} \mathrm{~N}_{3} \mathrm{O}_{2}$ : C, 68.38; H, 5.00; N, 7.72\%; found: C, 68.59; H, 5.15; N, 7.60\%.

Spiro[2.3"] oxindole-spiro[3.3']-5'-(4-bromophenylmethylidene)tetrahydro-4'(1H)-pyridinone-4-(4bromophenyl)hexahydro-1H-pyrrolizine (61). Obtained as a pale yellow solid, (0.136 g, 93\%); $\mathrm{mp}=207-208{ }^{\circ} \mathrm{C}$; IR (KBr): 1612, 1619, 1702, $3389 \mathrm{~cm}^{-1} ;{ }^{1} \mathrm{H}-\mathrm{NMR}\left(300 \mathrm{MHz}, \mathrm{CDCl}_{3}\right): \delta_{\mathrm{H}} 1.52-2.07$ $\left(\mathrm{m}, 4 \mathrm{H}, 5-\mathrm{CH}_{2}\right.$ and $\left.6-\mathrm{CH}_{2}\right), 2.29\left(\mathrm{~d}, 1 \mathrm{H}, J=13.2 \mathrm{~Hz}, 2^{\prime}-\mathrm{CH}_{2}\right), 2.58-2.62\left(\mathrm{~m}, 1 \mathrm{H}, 7-\mathrm{CH}_{2}\right), 3.06-3.14$ (m, $\left.1 \mathrm{H}, 7-\mathrm{CH}_{2}\right), 3.47$ (d, $\left.1 \mathrm{H}, J=15.6 \mathrm{~Hz}, 6{ }^{\prime}-\mathrm{CH}_{2}\right), 3.75\left(\mathrm{dd}, 1 \mathrm{H}, J=15.6,2.1 \mathrm{~Hz}, 6{ }^{\prime}-\mathrm{CH}_{2}\right), 4.05-4.15$ (m, 1H, 2'- $\left.\mathrm{CH}_{2}\right), 4.33$ (d, 1H, $\left.J=11.1 \mathrm{~Hz}, 4-\mathrm{CH}\right), 4.51-4.56(\mathrm{~m}, 1 \mathrm{H}, 4 \mathrm{a}-\mathrm{CH}), 6.69$ (d, 1H, $J=7.8 \mathrm{~Hz}$, $\mathrm{Ar}-\mathrm{H}), 6.81-7.55$ (m, 12H, Ar-H and arylmethylidene), 8.60 (s, 1H, 1"-NH). ${ }^{13} \mathrm{C}-\mathrm{NMR}(75 \mathrm{MHz}$, $\left.\mathrm{CDCl}_{3}\right): \delta_{\mathrm{C}} 26.10,28.98,48.35,48.76,49.25,53.28,64.98,71.85,74.12,110.41,121.80,122.84$, $123.92,128.06,129.83,131.64,131.77,131.92$, 132.17, 132.25, 132.39, 134.32, 135.44, 136.23, 141.81, 180.70, 201.52. Anal. calcd for $\mathrm{C}_{31} \mathrm{H}_{27} \mathrm{Br}_{2} \mathrm{~N}_{3} \mathrm{O}_{2}$ : C, 58.79; H, 4.30; N, 6.63\%; found: C, 58.96; H, 4.47; N, 6.51\%.

Spiro[2.3"] oxindole-spiro[3.3']-5'-(4-fluorophenylmethylidene)tetrahydro-4'(1 H)-pyridinone-4-(4fluorophenyl)hexahydro-1H-pyrrolizine (6m). Obtained as a pale yellow solid, (0.154 g, 94\%); $\mathrm{mp}=192-193{ }^{\circ} \mathrm{C}$; IR (KBr): 1611, 1620, 1701, $3390 \mathrm{~cm}^{-1} ;{ }^{1} \mathrm{H}-\mathrm{NMR}\left(500 \mathrm{MHz}, \mathrm{CDCl}_{3}\right): \delta_{\mathrm{H}} 1.50-2.03$ $\left(\mathrm{m}, 4 \mathrm{H}, 5-\mathrm{CH}_{2}\right.$ and $\left.6-\mathrm{CH}_{2}\right), 2.30\left(\mathrm{~d}, 1 \mathrm{H}, J=13.5 \mathrm{~Hz}, 2^{\prime}-\mathrm{CH}_{2}\right), 2.57-2.65\left(\mathrm{~m}, 1 \mathrm{H}, 7-\mathrm{CH}_{2}\right), 3.03-3.12$ (m, $\left.1 \mathrm{H}, 7-\mathrm{CH}_{2}\right), 3.37$ (d, $\left.1 \mathrm{H}, J=15.0 \mathrm{~Hz}, 6^{\prime}-\mathrm{CH}_{2}\right), 3.77$ (d, $1 \mathrm{H}, J=15.0,2.1 \mathrm{~Hz}, 6{ }^{\prime}-\mathrm{CH}_{2}$ ), 4.06-4.13 
(m, 1H, 2'- $\left.\mathrm{CH}_{2}\right), 4.36$ (d, 1H, $\left.J=11.0 \mathrm{~Hz}, 4-\mathrm{CH}\right), 4.52-4.55$ (m, 1H, 4a-CH), 6.61-7.54 (m, 13H, Ar-H and arylmethylidene), $8.62(\mathrm{~s}, 1 \mathrm{H}, 1 "-\mathrm{NH}) .{ }^{13} \mathrm{C}-\mathrm{NMR}\left(125 \mathrm{MHz}, \mathrm{CDCl}_{3}\right): \delta_{\mathrm{C}} 25.67,28.54,47.84$, $48.47,48.70,52.83,64.51,69.60,74.93,109.99,115.12\left({ }^{2} J_{\mathrm{CF}}=20.0 \mathrm{~Hz}\right), 115.80\left({ }^{2} J_{\mathrm{CF}}=21.25 \mathrm{~Hz}\right)$, $122.41,125.59,127.73,128.70,130.40,131.71,132.13,132.52,133.61,135.17,141.52,161.95$ $\left({ }^{1} J_{\mathrm{CF}}=245.0 \mathrm{~Hz}\right), 163.01\left({ }^{1} J_{\mathrm{CF}}=250.0 \mathrm{~Hz}\right), 180.62,201.19$. Anal. calcd for $\mathrm{C}_{31} \mathrm{H}_{27} \mathrm{~F}_{2} \mathrm{~N}_{3} \mathrm{O}_{2}: \mathrm{C}, 72.78$; $\mathrm{H}, 5.32 ; \mathrm{N}, 8.21 \%$; found: C, 72.92; H, 5.54; N, 8.04\%.

Spiro[2.3"] oxindole-spiro[3.3']-5'-(1-naphthylmethylidene)tetrahydro-4'(1H)-pyridinone-4-(1naphthyl)hexahydro-1H-pyrrolizine (6n). Obtained as a yellow solid, $(0.139 \mathrm{~g}, 91 \%) ; \mathrm{mp}=158-159{ }^{\circ} \mathrm{C}$; IR (KBr): 1607, 1619, 1705, $3391 \mathrm{~cm}^{-1} ;{ }^{1} \mathrm{H}-\mathrm{NMR}\left(300 \mathrm{MHz}, \mathrm{CDCl}_{3}\right): \delta_{\mathrm{H}} 1.82-2.09\left(\mathrm{~m}, 4 \mathrm{H}, 5-\mathrm{CH}_{2}\right.$ and 6- $\left.\mathrm{CH}_{2}\right), 2.65-2.68\left(\mathrm{~m}, 1 \mathrm{H}, 7-\mathrm{CH}_{2}\right), 2.78\left(\mathrm{~d}, 1 \mathrm{H}, J=12.9 \mathrm{~Hz}, 2^{\prime}-\mathrm{CH}_{2}\right), 3.30-3.35\left(\mathrm{~m}, 1 \mathrm{H}, 7-\mathrm{CH}_{2}\right)$, $3.44\left(\mathrm{~d}, 1 \mathrm{H}, J=15.6 \mathrm{~Hz}, 6{ }^{\prime}-\mathrm{CH}_{2}\right), 3.87\left(\mathrm{~d}, 1 \mathrm{H}, J=15.6 \mathrm{~Hz}, 6^{\prime}-\mathrm{CH}_{2}\right), 4.22\left(\mathrm{~d}, 1 \mathrm{H}, J=12.6 \mathrm{~Hz}, 2^{\prime}-\mathrm{CH}_{2}\right)$, 4.44-4.50 (m, 1H, 4-CH), 4.68-4.73 (m, 1H, 4a-CH), 6.27 (s, 1H, arylmethylidene), 6.41-8.07 (m, $18 \mathrm{H}, \mathrm{Ar}-\mathrm{H}), 9.02(\mathrm{~s}, 1 \mathrm{H}, 1 "-\mathrm{NH}) .{ }^{13} \mathrm{C}-\mathrm{NMR}\left(75 \mathrm{MHz}, \mathrm{CDCl}_{3}\right): \delta_{\mathrm{C}} 25.99,28.74,48.00,48.68,49.30$, 51.14, 64.58, 70.98, 75.04, 110.30, 122.63, 124.62, 125.05, 125.30, 125.45, 125.75, 126.77, 127.16, $127.59,127.91,128.20,128.85,129.08,129.22,129.39,129.64,130.05,132.45,132.48,133.64$, $133.70,133.96,134.46,134.90,136.90,137.73,138.82,141.09,181.13,202.63$. Anal. calcd for $\mathrm{C}_{39} \mathrm{H}_{33} \mathrm{~N}_{3} \mathrm{O}_{2}$ : C, 81.37; H, 5.78; N, 7.30\%; found: C, 81.59; H, 5.60; N, 7.43\%.

\subsection{Cell Culture and Cell Proliferation Assay}

\subsubsection{Cell Culture}

Human ovarian adenocarcinoma cell line (SK-OV-3, ATCC no. HTB-77), human breast carcinoma (MDA-MB-231, ATCC no. HTB-26), and human lymphoblastic leukemia cell line (CCRF-CEM, ATCC no. CCL-119) obtained from American Type Culture Collection. The cells were grown on $75 \mathrm{~cm}^{2}$ cell culture flasks with RPMI-16 medium for CCRF-CEM cells and EMEM (Eagle's minimum essential medium) for SK-OV-3 and MDA-MB-231 cells, and supplemented with $10 \%$ fetal bovine serum, and $1 \%$ penicillin/streptomycin solution (10,000 units of penicillin and $10 \mathrm{mg}$ of streptomycin in $0.9 \% \mathrm{NaCl}$ ) in a humidified atmosphere of $5 \% \mathrm{CO}_{2}, 95 \%$ air at $37{ }^{\circ} \mathrm{C}$.

\subsubsection{Cell Proliferation Assay}

The cell proliferation assay was carried out using CellTiter 96 aqueous one solution cell proliferation assay kit (Promega, Madison, WI, USA). Briefly, upon reaching about $75 \%-80 \%$ confluency, SK-OV-3 (5,000 cells/well), MDA-MB-231 (5,000 cells/well), or CCRF-CEM (40,000 cells/well) were plated in 96-well microplate in $100 \mu \mathrm{L}$ media. After seeding for $24 \mathrm{~h}$, the cells were treated with $50 \mu \mathrm{M}$ compound in triplicate. Doxorubicin $(10 \mu \mathrm{M})$ was used as the positive control. At the end of the sample exposure period $(72 \mathrm{~h})$, CellTiter 96 aqueous solution $(20 \mu \mathrm{L})$ was added. The plate was returned to the incubator for $1 \mathrm{~h}$ in a humidified atmosphere at $37^{\circ} \mathrm{C}$. The absorbance of the formazan product was measured at $490 \mathrm{~nm}$ using a microplate reader. The blank control was recorded by measuring the absorbance at $490 \mathrm{~nm}$ with wells containing medium mixed with CellTiter 96 aqueous solution but no cells. Results were expressed as the percentage of the control (without compound set at 
$100 \%$ ). The percentage of cell survival was calculated as [OD value of cells treated with the test compound - OD value of culture medium $] /[$ (OD value of control cells - OD value of culture medium) $] \times 100 \%$.

\subsection{3. $\mathrm{IC}_{50}$ Determination Assay}

$\mathrm{IC}_{50}$ determination assay was performed by CellTiter 96 aqueous one solution cell proliferation assay kit (Promega). Briefly, SK-OV-3 (5,000 cells/well) and CCRF-CEM (40,000 cells/well) were seeded in 96-well plate in media $(100 \mu \mathrm{L})$. After $24 \mathrm{~h}$, the cells were treated with various concentrations of compounds $(1-100 \mu \mathrm{M})$ in triplicate. After $72 \mathrm{~h}$ of incubation, $20 \mu \mathrm{L}$ CellTiter 96 aqueous solution was added to wells. The plate was kept in the incubator for $1 \mathrm{~h}$ in a humidified atmosphere at $37{ }^{\circ} \mathrm{C}$. The absorbance of the formazan product was measured at $490 \mathrm{~nm}$ using microplate reader. The blank control was recorded by measuring the absorbance at $490 \mathrm{~nm}$ with wells containing medium mixed with CellTiter 96 aqueous solution but no cells. The $\mathrm{IC}_{50}$ values were extrapolated from concentration-effect curves using non-linear regression analysis in GraphPad Prism $^{\circledR}$, version 5.03 .

\section{Conclusions}

In conclusion, azomethine ylides generated via an in situ reaction between $1 H$-indole-2,3-dione with $N$-methylglycine, phenylglycine, or proline underwent [3+2]-cycloaddition with 3,5-bis[$[(E)$ arylmethylidene]tetrahydro-4(1H)-pyridinones to afford different classes of spiropyrrolidines/pyrrolizines. A number of compounds exhibited antiproliferative activity against MDA-MB-231, CCRF-CEM, and SK-OV-3 cells. In general, most of the spiro-pyrrolizines derivatives showed higher antiproliferative activity when compared with $N$-methyl spiro-pyrrolidines and $N$ - $\alpha$-phenyl substituted spiro-pyrrolidines derivatives. Compounds $\mathbf{6 a}, \mathbf{6 b}$, and $\mathbf{6 m}$ were found to be the most potent derivatives showing $64 \%, 87 \%$, and $74 \%$ antiproliferative activity in MDA-MB-231, SK-OV-3, and CCRF-CEM cells, respectively. These lead compounds will be studied for their stereochemistry properties and have the potential as antiproliferative agents after further optimization.

\section{Supplementary Materials}

Supplementary materials can be accessed at: http://www.mdpi.com/1420-3049/19/7/10033/s1.

\section{Acknowledgments}

We thank National Center for Research Resources, NIH, and Grant Number and Grant Number 8 P20 GM103430-12 for sponsoring the core facility. The authors acknowledge the Deanship of Scientific Research at King Saud University for the Research Grant RGP-VPP-026.

\section{Author Contributions}

The contributions of the respective authors are as follows: R.K., F.B., H.O., R.I., T.S.C.,A.I.A., AND M.A.A. design and synthesis of compounds and A.S., B.S., K.M., A.N., and K.P. performed cell-based assays and provide SAR. The manuscript was written by K.P., M.A.A., and A. S. 


\section{Conflicts of Interest}

The authors declare no conflict of interest.

\section{References}

1. Domling, A.; Ugi, I. Multicomponent reactions with isocyanides. Angew. Chem. Int. Ed. 2000, 39, 3168-3210.

2. Orru, R.V.A.; de Greef, M. Recent advances in solution-phase multicomponent methodology for the synthesis of heterocyclic compounds. Synthesis 2003, 10, 1471-1499.

3. Zhu, J. Recent developments in the isonitrile-based multicomponent synthesis of heterocycles. Eur. J. Org. Chem. 2003, 7, 1133-1144.

4. Guillena, G.; Ramon, D.J.; Yus, M. Organocatalytic enantioselective multicomponent reactions (OEMCRs). Tetrahedron: Asymmetry 2007, 18, 693-700.

5. Estevez, V.; Villacampa, M.; Menendez, J.C. Multicomponent reactions for the synthesis of pyrroles. Chem. Soc. Rev. 2010, 39, 4402-4421.

6. Wender, P.A.; Verma, V.A.; Paxton, T.J.; Pillow, T.H. Function-oriented synthesis, step economy, and drug design. Accounts Chem. Res. 2008, 41, 40-49.

7. Trost, B.M. On inventing reactions for atom economy. Accounts Chem. Res. 2002, 35, 695-705.

8. Burns, N.Z.; Baran, P.S.; Hoffmann, R.W. Redox economy in organic synthesis. Angew. Chem. Int. Ed. 2009, 48, 2854-2867.

9. Newhouse, T.; Baran, P.S.; Hoffmann, R.W. The economies of synthesis. Chem. Soc. Rev. 2009, 38, 3010-3021.

10. Hulme, C.; Gore, V. "Multi-component reactions: Emerging chemistry in drug discovery" "from xylocain to crixivan'. Curr. Med. Chem. 2003, 10, 51-80.

11. Schreiber, S.L. Target-oriented and diversity-oriented organic synthesis in drug discovery. Science 2000, 287, 1964-1969.

12. Spring, D.R. Diversity-oriented synthesis; A challenge for synthetic chemists. Org. Biomol. Chem. 2003, 1, 3867-3870.

13. Burke, M.D.; Berger, E.M.; Schreiber, S.L. Generating diverse skeletons of small molecules combinatorially. Science 2003, 302, 613-618.

14. Burke, M.D.; Schreiber, S.L. A planning strategy for diversity-oriented synthesis. Angew. Chem. Int. Ed. 2004, 43, 46-58.

15. Spandl, R.J.; Bender, A.; Spring, D.R. Diversity-oriented synthesis; a spectrum of approaches and results. Org. Biomol. Chem. 2008, 6, 1149-1158.

16. Padwa, A. 1,3-Dipolar Cycloaddition Chemistry; Wiley: New York, NY, USA, 1984; Volumes 1 and 2.

17. Grigg, R.; Sridharan, V. Advances in Cycloaddition; Curran, D.P., Ed.; Jai: London, UK, 1993; Volume 3, pp. 161-204.

18. Gothelf, K.; Jorgensen, K.A. Asymmetric 1,3-dipolar cycloaddition reactions. Chem. Rev. 1998, 98, 863-910. 
19. Monlineux, R.J. In Alkaloids: Chemical and Biological Perspective; Pelletier, S.W., Ed.; Wiley: New York, NY, USA, 1987.

20. Tsukamoto, K.; Uno, A.; Shimada, S.; Imokaw, G. Nojirimycin Inhibits Pulmonary Metastasis of B16-F10 Murine Melanoma-Cells, G. Clin. Res. 1989, 37A, 722.

21. El-Subbagh, H.I.; Abu-Zaid, S.M.; Mahran, M.A.; Badria, F.A.; Al-Obaid, A.M. Synthesis and biological evaluation of certain alpha,beta-unsaturated ketones and their corresponding fused pyridines as antiviral and cytotoxic agents. J. Med. Chem. 2000, 43, 2915-2921.

22. Dimmock, J.R.; Padmanilayam, M.P.; Puthucode, R.N.; Nazarali, A.J.; Motaganahalli, N.L.; Zello, G.A.; Quail, J.W.; Oloo, E.O.; Kraatz, H.B.; Prisciak, J.S.; et al. A conformational and structure-activity relationship study of cytotoxic 3,5-bis(arylidene)-4-piperidones and related $N$-acryloyl analogues. J. Med. Chem. 2001, 44, 586-593.

23. Kumar, R.J.; Perumal, S.; Senthilkumar, P.; Yogeeswari, P.; Sriram, D. Discovery of antimycobacterial spiro-piperidin-4-ones: An atom economic, stereoselective synthesis, and biological intervention. J. Med.Chem. 2008, 51, 5731-5735.

24. Govind, M.M.; Selvanayagam, S.; Velmurugan, D.; Ravikumar, K.; Sridhar, G.; Raghunathan, R. 5"-Benzy-lidene-1'-methyl-4'-phenylindole-3-spiro-2'-pyrrolidine-3'-spiro-3"-piperidine2 4"dione. Acta Crystalorg. E 2003, 59, 1878-1880.

25. Girgis, A.S. Regioselective synthesis and stereochemical structure of anti-tumor active dispiro[3H-indole-3,2'-pyrrolidine-3',3"-piperidine]-2(1H),4"-diones. Eur. J. Med. Chem. 2009, 44, $1257-1264$.

26. Lee, H.K.; Chun, J.S.; Pak, C.S. Facile transformation of 3,4-disubstituted 2-azetidinones to chiral 5,6-dihydro-2-pyridones. Tetrahedron Lett. 2001, 42, 3483-3486.

27. Young-Won, C.; Angela, S.; Bao-Ning, S.; Quiwen, M.; Hee-Byung, C.; Soedarsono, R.; Leonardus, K.; Agus, R.; Norman, F.; Steven, S.; et al. Potential anticancer activity of naturally occurring and semisynthetic derivatives of aculeatins A and B from Amomum aculeatum. J. Nat. Prod. 2008, 71, 390-395.

28. Wang, W.-L.; Zhu, T.-J.; Tao, H.-W.; Lu, Z.-Y.; Fang, Y.-C.; Gu, Q.-Q.; Zhu, W.-M. Three novel, structurally unique spirocyclic alkaloids from the halotolerant B-17 fungal strain of Aspergillus variecolor. Chem. Biodivers. 2007, 4, 2913-2919.

29. Van-Der-Sar, S.; Blunt, J.; Munro, M. Spiro-Mamakone A: A unique relative of the spirobisnaphthalene class of compounds. Org. Lett. 2006, 8, 2059-2061.

30. Hyeong-Beom, P.; Hyun, J.N.; Hee, H.J.; Hoon, C.J.; Hoon, C.J.; Jung-Hyuck, C.; Ho, Y.K.; Chang-Hyun, O. Synthesis and in-vitro activity of novel 1beta-methylcarbapenems having spiro[2,4]heptane moieties. Arch. Pharm. 2007, 340, 530-537.

31. Krzysztof, K.; Jolanta, O.; Malgorzata, D. Synthesis, physicochemical and anticonvulsant properties of new $N$-phenylamino derivatives of 2-azaspiro[4.4]nonane- and [4.5]decane-1,3diones: Part V. Eur. J. Med. Chem. 2008, 43, 53-61.

32. Jolanta, O.; Krzysztof, K. Synthesis and anticonvulsant properties of new N-phenylamino derivatives of 2-azaspiro[4.4]nonane,2-azaspiro[4.5]decane-1,3-dione and 3-cyclohexyl pyrrolidine2,5-dione. Part IV. Acta Pol. Pharm. 2006, 6, 101-108. 
33. Jolanta, O.; Krzysztof, K.; Ewa, T. Impact of aromatic substitution on the anticonvulsant activity of new N-(4-arylpiperazin-1-yl)-alkyl-2-azaspiro[4,5]decane-1,3-dione derivatives. Pharmacol. Rep. 2006, 58, 207-214.

34. Wei, A.C.; Ali, M.A.; Yoon, Y.K.; Ismail, R.; Choon, T.S.; Kumar, R.S.; Arumugam, N.; Almansour, A.I.; Osman, H. Antimycobacterial activity: A facile three-component [3+2]cycloaddition for the regioselective synthesis of highly functionalised dispiropyrrolidines. Biol. Med. Chem. Lett. 2012, 22, 4930-4933.

35. Ali, M.A.; Samy, J.G.; Manogaran, E.; Sellappan, V.; Hasan, M.Z.; Ahsan, M.J.; Pandian, S.; ShaharYar, M. Synthesis and antimycobacterial evaluation of novel 5,6-dimethoxy-1-oxo-2,5dihydro-1H-2-indenyl-5,4-substituted phenyl methanone analogues. Biol. Med. Chem. Lett. 2009, 19, 7000-7002.

36. Ashraf Ali, M.; Ismail, R.; Choon, T.S.; Suresh Kumar, R.; Osman, H.; Arumugam, N.; Almansour, A.I.; Elumalai, K.; Singh, A. AChE inhibitor: A regio- and stereo-selective 1,3dipolar cycloaddition for the synthesis of novel substituted 5,6-dimethoxy spiro[5.3']-oxindolespiro-[6.3"]-2,3-dihydro-1H-inden-1"-one-7-(substitutedaryl)-tetrahydro- $1 H$-pyrrolo[1,2-c][1,3] thiazole. Biol. Med. Chem. Lett. 2012, 22, 508-512.

37. Wei, A.C.; Ali, M.A.; Yoon, Y.K.; Ismail, R.; Choon, T.S.; Kumar, R.S. A facile three-component $[3+2]$-cycloaddition for the regioselective synthesis of highly functionalised dispiropyrrolidines acting as antimycobacterial agents. Biol. Med. Chem. Lett. 2013, 23, 1383-1386.

38. Sarma, B.K.; Manna, D.; Minoura, M.; Mugesh, G. Synthesis, structure, spirocyclization mechanism, and glutathione peroxidase-like antioxidant activity of stable spirodiazaselenurane and spirodiazatellurane. J. Am. Chem. Soc. 2010, 132, 5364-5374.

39. Shimakawa, S.; Yoshida, Y.; Niki, E. Antioxidant action of a lipophilic nitroxyl radical, cyclohexane-1-spiro-2'-(4'-oxyimidazolidine-1'-oxyl)-5'-spiro-1"-cyclohexane, against lipid peroxidation under hypoxic conditions. Lipids 2003, 38, 225-231.

Sample Availability: Samples of the compounds are available from the authors for a short period of time.

(C) 2014 by the authors; licensee MDPI, Basel, Switzerland. This article is an open access article distributed under the terms and conditions of the Creative Commons Attribution license (http://creativecommons.org/licenses/by/3.0/). 